ARTICLE

https://doi.org/10.1038/s41467-019-08780-3

\title{
The companion of cellulose synthase 1 confers salt tolerance through a Tau-like mechanism in plants
}

Christopher Kesten 1,2,3, Arndt Wallmann ${ }^{4}$, René Schneider ${ }^{2,3}$, Heather E. McFarlane ${ }^{2}$, Anne Diehl ${ }^{4}$, Ghazanfar Abbas Khan², Barth-Jan van Rossum ${ }^{4}$, Edwin R. Lampugnani ${ }^{2}$, Witold G. Szymanski ${ }^{3}$, Nils Cremer ${ }^{4}$, Peter Schmieder ${ }^{4}$, Kristina L. Ford ${ }^{2}$, Florian Seiter ${ }^{4}$, Joshua L. Heazlewood ${ }^{2}$, Clara Sanchez-Rodriguez ${ }^{1}$, Hartmut Oschkinat ${ }^{4} \&$ Staffan Persson ${ }^{2,3}$

Microtubules are filamentous structures necessary for cell division, motility and morphology, with dynamics critically regulated by microtubule-associated proteins (MAPs). Here we outline the molecular mechanism by which the MAP, COMPANION OF CELLULOSE SYNTHASE1 (CC1), controls microtubule bundling and dynamics to sustain plant growth under salt stress. CC1 contains an intrinsically disordered $\mathrm{N}$-terminus that links microtubules at evenly distributed points through four conserved hydrophobic regions. By NMR and live cell analyses we reveal that two neighboring residues in the first hydrophobic binding motif are crucial for the microtubule interaction. The microtubule-binding mechanism of CC1 is reminiscent to that of the prominent neuropathology-related protein Tau, indicating evolutionary convergence of MAP functions across animal and plant cells.

\footnotetext{
${ }^{1}$ Department of Biology, ETH Zurich, 8092 Zurich, Switzerland. ${ }^{2}$ School of Biosciences, University of Melbourne, Parkville, 3010 Victoria, Australia. ${ }^{3}$ Max-Planck-Institute of Molecular Plant Physiology, Am Mühlenberg 1, 14476 Potsdam-Golm, Germany. ${ }^{4}$ Leibniz-Forschungsinstitut für Molekulare Pharmakologie (FMP), NMR-supported Structural Biology, Robert-Rössle-Str. 10, 13125 Berlin, Germany. These authors contributed equally: Christopher Kesten, Arndt Wallmann. Correspondence and requests for materials should be addressed to H.O. (email: oschkinat@fmp-berlin.de) or to S.P. (email: Staffan.persson@unimelb.edu.au)
} 
$\mathrm{M}$ icrotubules are tubular structures essential to morphogenesis, division and motility in eukaryotic cells ${ }^{1}$. While animal cells typically contain a centrosome with radiating microtubules toward the cell periphery, growing plant cells arrange their microtubules along the cell cortex ${ }^{2}$. A major function of the cortical microtubules in plant cells is to direct the synthesis of cellulose, a fundamental component of the cell wall essential to plant morphology ${ }^{3}$. Cellulose is produced at the plasma membrane by cellulose synthase (CESA) protein complexes $\left(\mathrm{CSCs}^{4}\right)$ that display catalytically driven motility along the membrane ${ }^{3}$. The recently described microtubule-associated protein (MAP), COMPANION OF CELLULOSE SYNTHASE 1 (CC1), is an integral component of the CSC and sustains cellulose synthesis by promoting the formation of a stress-tolerant microtubule array during salt stress ${ }^{5}$. As cellulose synthesis is key for plant growth, engineering of plants to better produce cellulose is of utmost importance to agriculture. Indeed, understanding the molecular mechanism by which $\mathrm{CC} 1$ controls cellulose synthesis may bear opportunities to improve cultivation on salt-affected lands.

The microtubule network is highly dynamic, and its state is influenced by the action of MAPs. The mammalian Tau/MAP2/ MAP4 family represents the most investigated MAP set, primarily due to Tau's importance in the pathology of neurodegenerative diseases $^{6-8}$. In vitro, Tau promotes polymerization and bundling of microtubules, and diffuses along the microtubule lattice ${ }^{9-11}$. In the brain, Tau is predominantly located at the axons of neurons, where it contributes to the microtubule organization that drives neurite outgrowth ${ }^{12,13}$. In disease, Tau self-aggregates into neurofibrillary tangles that might trigger neurodegeneration ${ }^{14}$. Intriguingly, no clear homologs of the Tau/MAP2/MAP4 family have been identified in plants ${ }^{15,16}$. Because, the full scope of Tau's biological role remains elusive, identification of Tau-related proteins outside the animal Kingdom would benefit our understanding of how this class of MAPs functions.

In this study, we unravel the microtubule-binding mechanism of $\mathrm{CC} 1$ and show that it is reminiscent to that of Tau, indicating evolutionary convergence of MAP functions across animal and plant cells.

\section{Results}

The N-terminus of CC1 bundles microtubules. The cytosolic Nterminal part of CC1 (residues 1-120, CC1 $\Delta$ C223) binds to microtubules and restores microtubule reassembly, cellulose synthesis and wild-type growth of $c c 1 c c 2$ (null-mutation in CC1 and its closest homolog CC2) seedlings on high levels of salt ${ }^{5}$. These data indicate that $\mathrm{CC} 1 \Delta \mathrm{C} 223$ is critical to CCl's function during stress, and we therefore set out to investigate the molecular details of how it interacts with microtubules. We crosslinked $6 x$ His-tagged $\mathrm{CC} 1 \Delta \mathrm{C} 223$ with $\alpha$ - $\beta$-tubulin dimers using 1 ethyl-3-(3-dimethylaminopropyl) carbodiimide hydrochloride $(\mathrm{EDC})^{17}$, which led to di- and multimeric protein products (Fig. 1a, Supplementary Fig. 1a). We used EDC, which links functional groups of lysine to either aspartate or glutamate, and not the typical sulfhydryl-reactive or lysine-lysine cross-linkers, as $\mathrm{CC} 1 \Delta \mathrm{C} 223$ only contains a single cysteine and has a basic isoelectric point (pI) (i.e. the main reactive amino acid is lysine), while tubulin/microtubules have an acidic pI (i.e. the main reactive amino acids on the surface of the tubulin dimer are aspartate and glutamate). After LC/MS/MS analysis, we used four different software packages (StavroX, pLink, SIM-XL, Crux ${ }^{18-21}$ ) to identify potential inter-cross-links between tubulin and $\mathrm{CC} 1 \Delta \mathrm{C} 223$. Extensive manual curation resulted in five welldefined covalent bonds between $\mathrm{CC} 1 \Delta \mathrm{C} 223$ and $\alpha$ - or $\beta$-tubulin (Fig. 1b). We consistently detected four peptides of CC1 $\Delta \mathrm{C} 223$ cross-linked to $\beta$-tubulin $\left(\mathrm{K}^{40}-\mathrm{E}^{111}, \mathrm{~K}^{94}-\mathrm{E}^{111}, \mathrm{~K}^{96}-\mathrm{E}^{111}\right.$ and $\mathrm{K}^{96}-\mathrm{E}^{158}$; letters and numbers indicate amino acids in CC1 $\Delta \mathrm{C} 223$ and $\beta$-tubulin, respectively; Fig. 1b, c; Supplementary Table 2 and Supplementary Fig. lb-h). Notably, the three sequentially distant $\mathrm{K}^{40}$ and $\mathrm{K}^{94 / 96}$ of $\mathrm{CC} 1 \Delta \mathrm{C} 223$ cross-linked to the same residue on $\beta$-tubulin ( $\left.\mathrm{E}^{111}\right)$. This suggests that two $\mathrm{CC} 1$ regions might bind the same sites on two different $\beta$-tubulin molecules, which is corroborated by the multimeric protein products in the SDS page. The cross-linked position on a-tubulin is close to the hydrophobic interface between tubulin heterodimers, a site that is frequently occupied by agents that directly regulate microtubule formation, such as vinblastine, the stathmin-like domain (SLD) of RB3, and also by Tau 22-24 (Supplementary Fig. 2a-b).

To further investigate how CC1 $\Delta \mathrm{C} 223$ binds microtubules, we co-polymerized tubulin in the presence of $\mathrm{CC} 1 \Delta \mathrm{C} 223$. We then labeled $\mathrm{CC} 1 \Delta \mathrm{C} 223$ using $5 \mathrm{~nm}$ gold-conjugates that recognize the His-tag 25 and monitored the formed microtubules and gold distribution via transmission electron microscopy (TEM). Gold labeling only occurred at closely aligned microtubules with very small inter-microtubule distances (Fig. 1d, e, Supplementary Fig. 1d-e), and were visible as evenly distributed foci in straight rows along interphases of two neighboring microtubules (Fig. 1d, e), while a negative control employing BSA did not show any specific microtubule labeling (Supplementary Fig. 2c). The gold particles were typically spaced by $10 \mathrm{~nm}$ (Fig. 1f; $10.0 \mathrm{~nm} \pm 2.4$ $\mathrm{nm}$; mean \pm S.D.; three-independent experiments; $n=1785$ labels). The number of gold-labels in a given row ranged between two and 41 labels (Fig. 1g; $8 \pm 5$ labels; mean \pm S.D; three independent replicates; $n=274$ rows), making each row about 80 $\mathrm{nm}$ in length. We also observed multiple gold-labeled rows on one microtubule when in close proximity to several other microtubules (Supplementary Fig. 2d). The angles between gold-labeled rows were small (Fig. $1 \mathrm{~h} ; 2.8^{\circ} \pm 3^{\circ}$; mean \pm S.D.; three-independent replicates; $n=98$ rows), highlighting that the labeling did not shift between neighboring protofilaments on the same microtubule. These data indicate that $\mathrm{CC} 1 \Delta \mathrm{C} 223$ promotes microtubule bundling. Indeed, increasing levels of $\mathrm{CC} 1 \Delta \mathrm{C} 223$ correlated with increased microtubule bundling in TEM experiments (Fig. 2a, b), while a BSA control did not show increased bundling (Supplementary Fig. 3a, b).

The CC1 N-terminus can diffuse along the microtubule lattice. As our TEM experiments only provide static information on the interactions between $\mathrm{CC} 1 \Delta \mathrm{C} 223$ and microtubules, we labelled the sole sulfhydryl group $\left(\mathrm{C}^{116}\right)$ in $\mathrm{CC} 1 \Delta \mathrm{C} 223$ with the green fluorescent dye CF488A-maleimide (Supplementary Fig. 3c) and performed rhodamine-labeled microtubule interaction assays ${ }^{26}$. Using total internal reflection fluorescence microscopy, we observed most of the CF488A-labeled CC1 $\Delta \mathrm{C} 223$ proteins as fluorescent foci associated with microtubules (Fig. 2c, Supplementary Movie 1). CF488A-labeled CC1 $\triangle \mathrm{C} 223$ diffused bidirectionally along the rhodamine-labeled microtubules and occurred on both single and bundled microtubules (Fig. 2d). In accordance with the results above, CF488A-labeled foci occupied bundled microtubules for a longer time than single microtubules (Fig. 2e, Supplementary Fig. 3d-e). The diffusion coefficient $\left(0.076 \pm 0.007 \mu \mathrm{m}^{2} \mathrm{~s}^{-1}\right.$; mean \pm S.D.; $n=50$ molecules) of fluorescent foci exhibited a linear relationship with time (Supplementary Fig. 3f), indicating free diffusion. These data are reminiscent to that of Tau, which promotes microtubule-bundling and polymerization, and also moves along microtubules in vitro with comparable diffusion coefficients $\left(0.142-0.292 \mu \mathrm{m}^{2} \mathrm{~s}^{-110}\right)$.

The N-terminus of $\mathrm{CCl}$ is intrinsically unstructured. To understand how $\mathrm{CC} 1 \Delta \mathrm{C} 223$ engages with microtubules, we 
a

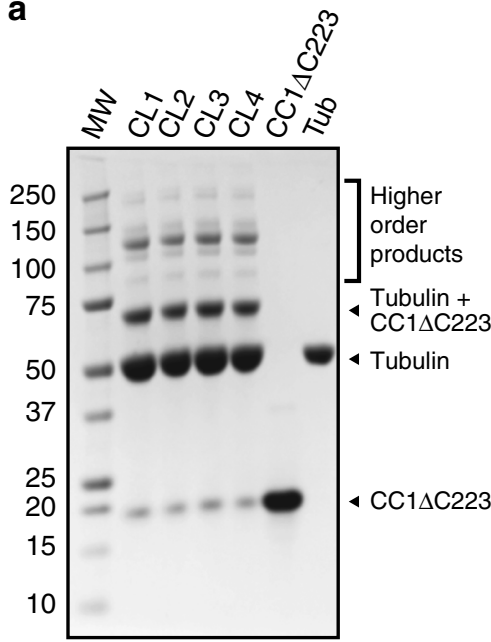

b

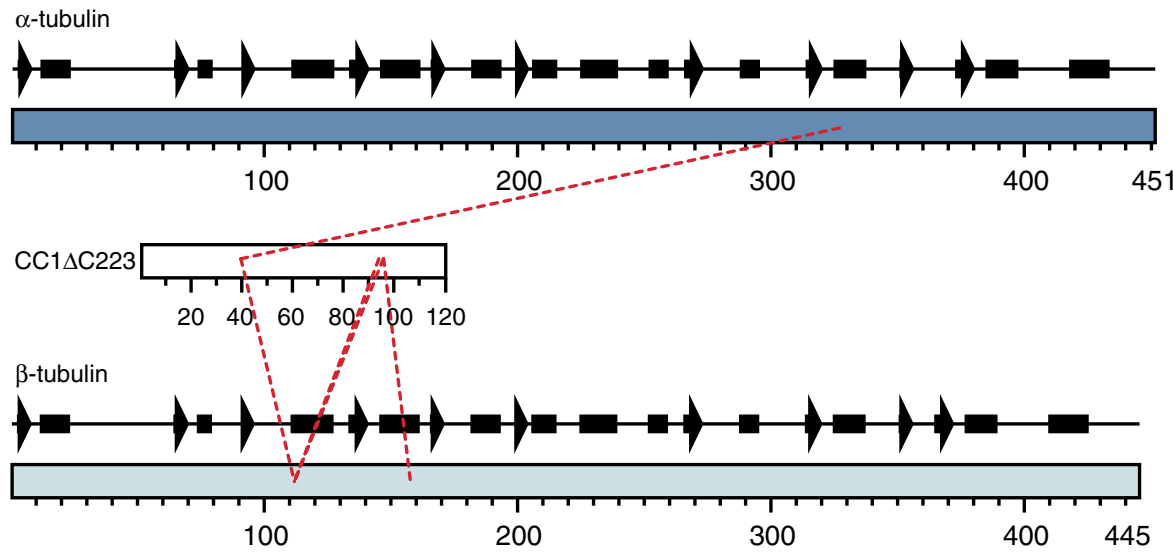

C

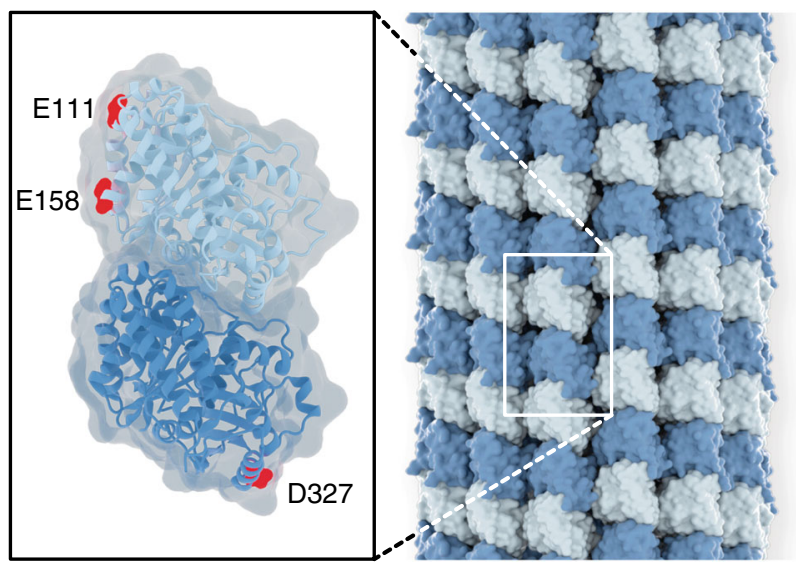

e

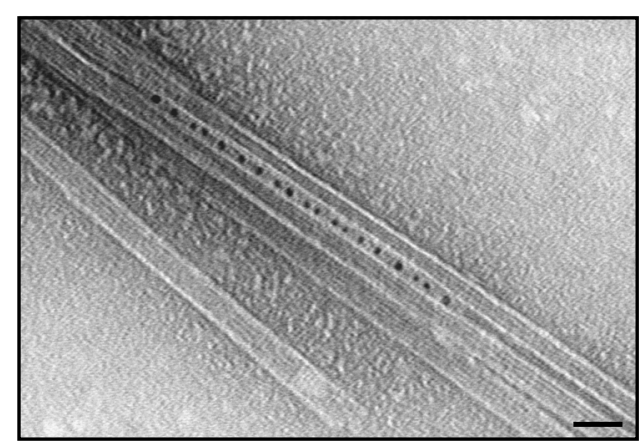

f

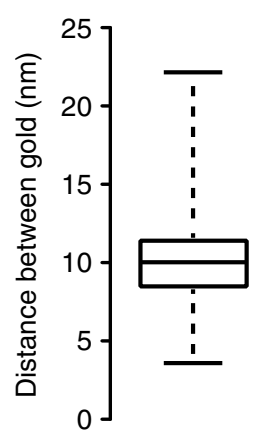

d

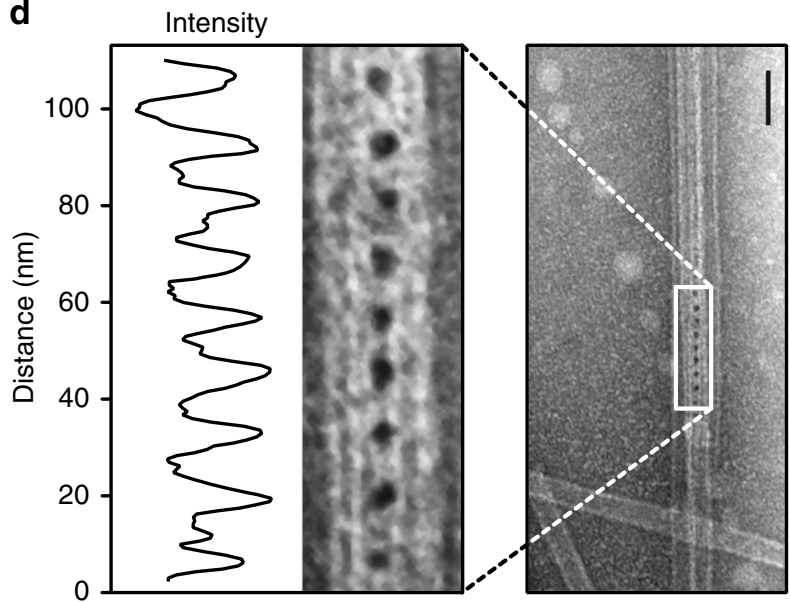

g

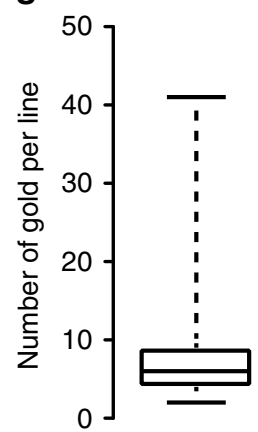

h

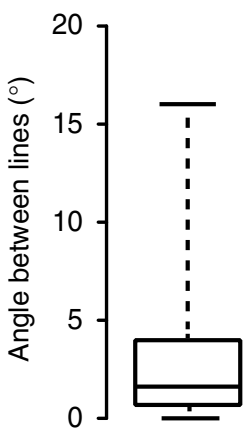

Fig. 1 The $\mathrm{N}$-terminus of $\mathrm{CC} 1$ binds sites on both $\alpha$ - and $\beta$-Tubulin and cross-links microtubules. a SDS-Page of EDC-induced cross-linking of $6 x H$ His-CC1 $1 \Delta$ C223 $(16 \mathrm{kDa})$ and tubulin dimers $(2 \times 55 \mathrm{kDa})$. Arrowheads depict position of relevant protein bands. MW molecular weight marker, CL1-4 cross-linking reaction 1-4. Higher order cross-linking products represent cross-links between e.g. tubulin $+2 \times C C 1 \Delta C 223(87 \mathrm{kDa})$, tubulin dimers (110 kDa), tubulin dimers $+\mathrm{CC} 1 \Delta \mathrm{C} 223$ $(126 \mathrm{kDa})$, tubulin dimers $+2 \times \mathrm{CC} 1 \Delta \mathrm{C} 223(142 \mathrm{kDa})$. b Schematic views of the secondary structures of $\alpha$ - and $\beta$-tubulin, and the CC1 $\Delta$ C223 sequence. Dashed lines depict detected cross-linking positions of $\mathrm{CC} 1 \Delta \mathrm{C} 223$ and $\alpha$ - or $\beta$-tubulin. $\mathbf{c}$ Projection of detected cross-links onto an $\alpha / \beta$-tubulin dimer (PDB code 1 tub). Dark blue $=\alpha$-tubulin; Light blue $=\beta$-tubulin; Sites for cross-linked amino acids are marked in red. $\mathbf{d}$ Representative TEM image of CC1 $\Delta$ C223 distribution along negatively stained, taxol-stabilized microtubules polymerized in the presence of 6 xHis-CC1 $\triangle \mathrm{C} 223$. CC1 $\Delta \mathrm{C} 223$ protein is visualized by a $5 \mathrm{~nm}$ gold-conjugated Ni-NTA tag that recognizes 6 xHis-tagged proteins. A transect was taken along rows of gold particles, and dips in the light intensity along the transect correspond to gold particle centers. Note the even distribution of the electron-dense gold particles in between neighboring microtubules. Scale bar $=50 \mathrm{~nm}$. e CC1 $\triangle$ C223 distribution along negatively stained, taxol-stabilized microtubules polymerized in the presence of $6 x H i s-C C 1 \Delta C 223$. CC1 $\Delta C 223$ can form a zipper-like pattern that links microtubules. Scale bar $=100 \mathrm{~nm}$. $\mathbf{f}$ Quantification of the distance between individual gold particles as shown in $\mathbf{d}$ and $\mathbf{e}$ (box plot: Center lines show the medians; box limits indicate the 25th and 75th percentiles; whiskers extend to the minimum and maximum). $\mathbf{g}$, $\mathbf{h}$ Quantification of number of gold labels per row $(\mathbf{g})$ and the angle between adjacent gold-labeled rows (h) from images as those in $\mathbf{d}$ and $\mathbf{e}$ (box plots: Center lines show the medians; box limits indicate the 25th and 75th percentiles; whiskers extend to the minimum and maximum) 
a

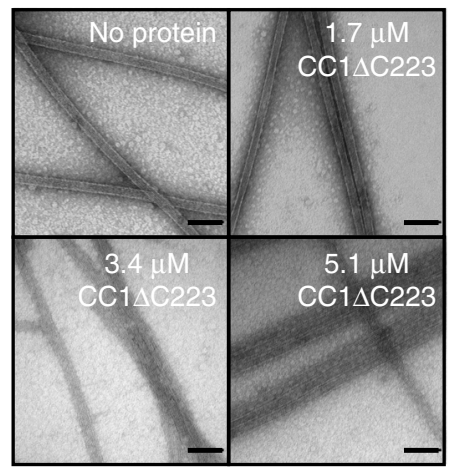

b

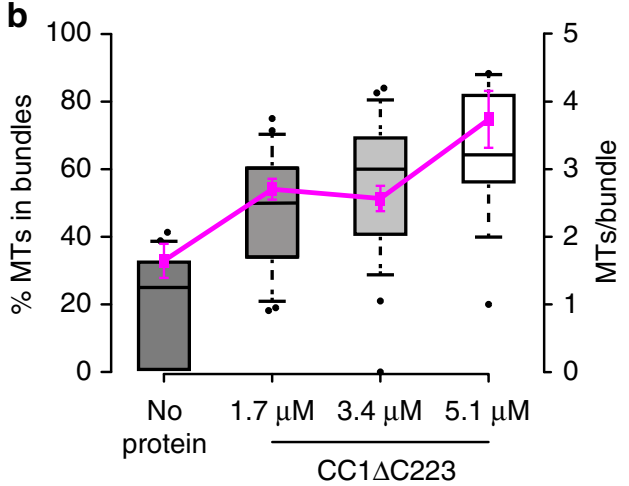

C
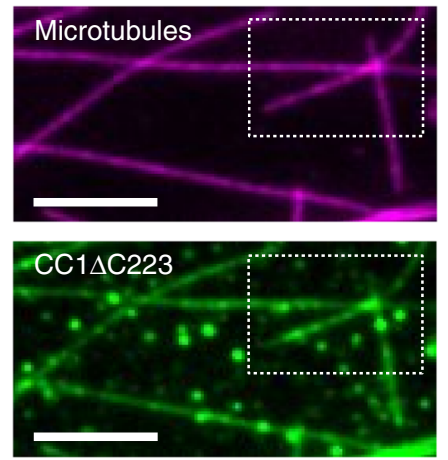

e

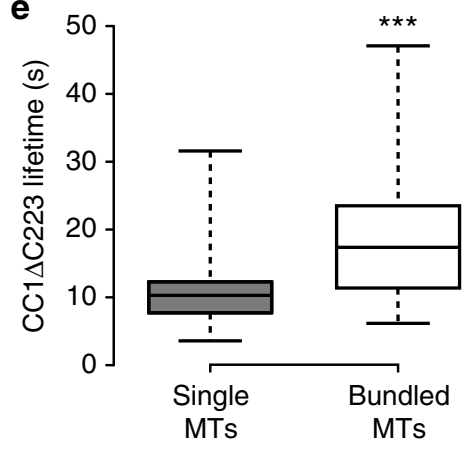

d

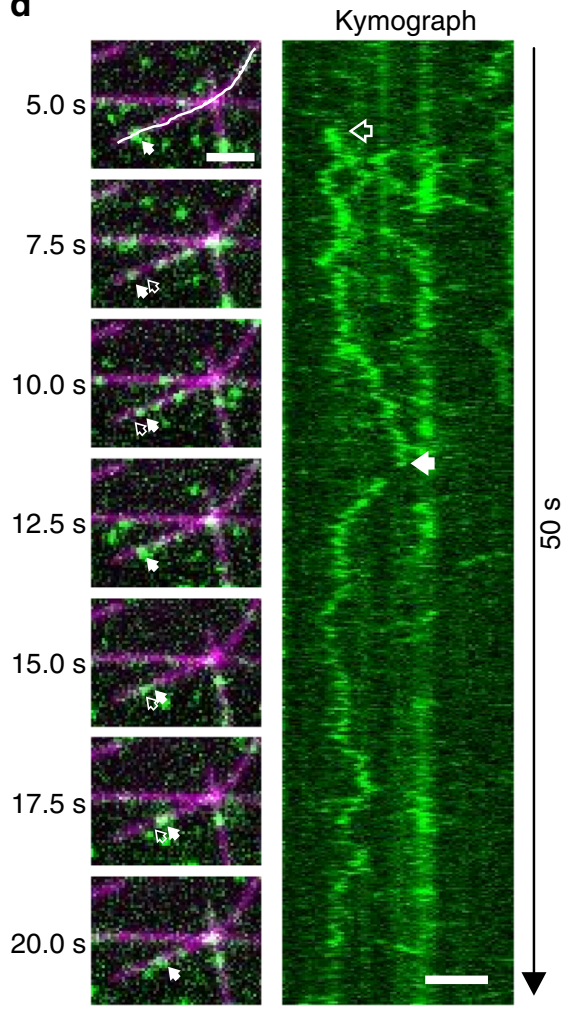

Fig. 2 The $\mathrm{N}$-terminus of $\mathrm{CC} 1$ induces microtubule bundling and can diffuse along the microtubule lattice. a Transmission electron microscopy (TEM) of negatively stained taxol-stabilized microtubules after addition of increasing levels of $6 x \mathrm{His}-\mathrm{CC} 1 \Delta \mathrm{C} 223$ during microtubule polymerization. Note that it is very difficult to discern individual microtubules in the microtubule bundles after addition of $\sim 3 \mu \mathrm{M}$ of CC1 $\Delta$ C223. Scale bars $=100 \mathrm{~nm}$. $\mathbf{b}$ Quantification of the proportion of microtubules in bundles (left $y$-axis, box plots: Center lines show the medians; box limits indicate the 25th and 75th percentiles; whiskers extend to the 10th and 90th percentiles, outliers are represented by dots) and number of microtubules/bundle (right $y$-axis, magenta line: mean \pm SEM) with increasing concentration of $6 \times \mathrm{His}-\mathrm{CC} 1 \Delta \mathrm{C} 223$ (quantified from images such as those in a). c CF488A-labeled $6 \times \mathrm{His}-\mathrm{CC} 1 \Delta \mathrm{C} 223$ proteins (green) associated with surface-bound microtubules (magenta) in vitro. Scale bar $=5 \mu \mathrm{m}$. d Time-series images (left panel) of CF488-labeled $6 \times \mathrm{xHis}-\mathrm{CC} 1 \Delta \mathrm{C} 223$ (green) diffusing along microtubules (magenta). Filled arrow = position in current frame, empty arrow $=$ position in previous frame. Scale bar $=2 \mu \mathrm{m}$. Representative kymograph (right panel) along solid line in left panel (top) showing diffusion of $6 x \mathrm{His}-\mathrm{CC} 1 \Delta \mathrm{C} 223$ foci. Scale bar $=2 \mu \mathrm{m}$. e $6 x \mathrm{His}-$ $\mathrm{CC} 1 \triangle \mathrm{C} 223$ lifetime on single versus bundled microtubules (box plots: Center lines show the medians; box limits indicate the 25th and 75th percentiles; whiskers extend to the minimum and maximum), $n=60$ single and 37 bundled microtubules, ${ }^{\star \star \star} p$-value $<0.001$, Welch's unpaired $t$-test)

assessed its structural features using "solution state" NMR, circular dichroism spectroscopy $(\mathrm{CD})$ and analytical ultracentrifugation (AUC). The $2 \mathrm{D}{ }^{1} \mathrm{H}-15 \mathrm{~N}$-heteronuclear single quantum coherence (HSQC) spectrum of ${ }^{15} \mathrm{~N}$-labeled $\mathrm{CC} 1 \Delta \mathrm{C} 223$ showed narrow signals and poor chemical shift dispersion in the ${ }^{1} \mathrm{H}$ dimension, which is characteristic for intrinsically disordered proteins (Fig. 3a). For the sequence-specific assignment, we used a combination of three-dimensional and four-dimensional experiments with non-uniform sampling to assign $\sim 85 \%$ of the backbone resonances. The disordered nature of $\mathrm{CC} 1 \Delta \mathrm{C} 223$ was supported via multiple sequence data analysis algorithms and $\mathrm{CD}$ measurements (Supplementary Fig. 4a, Fig. 3b). AUC analysis revealed only elongated monomeric forms of the protein in solution (Fig. 3c). To estimate local propensities for secondary structure formation, we determined neighbor-corrected structural propensities using the ncSPC algorithm ${ }^{27}$. Experimental $\mathrm{C} \alpha, \mathrm{C} \beta$ and $\mathrm{C}^{\prime}$ chemical shifts were subtracted from the reference random-coil state of the IDP-based ncIDP chemical shift library (Supplementary Fig. $4 \mathrm{~b}-\mathrm{d})^{28}$. The resulting propensity score revealed few and rather scattered deviations from random coil values (Fig. 3d). Moreover, the uniform and fast dynamics of $\mathrm{CC} 1 \Delta \mathrm{C} 223$ are consistent with a disordered, highly dynamic and monomeric state in solution (Supplementary Fig. $4 \mathrm{e}-\mathrm{g}$ ), similar to the members of the Tau/MAP2/MAP4 family.
CC1 engages with microtubules via four hydrophobic motifs. To study CC1 $\Delta \mathrm{C} 223$-microtubule interactions in a residue-specific manner, we recorded ${ }^{1} \mathrm{H}^{15} \mathrm{~N}$ HSQC spectra of ${ }^{15} \mathrm{~N}$-labeled $\mathrm{CC} 1 \Delta \mathrm{C} 223$ in the presence and absence of taxol-stabilized microtubules. We observed line broadening and vanishing of individual cross-peaks when microtubules were added (Fig. 4a, b). The effects of the microtubules on the transverse relaxation rate $\left(\Delta R_{2}\right)$ of $\mathrm{CC} 1 \Delta \mathrm{C} 223$ signals were reversible, residue specific, independent of the magnetic field, did not correlate with the chemical shift changes, and relaxation dispersion experiments did not show contributions of intermediate exchange (Supplementary Fig. 5a-g). To conclude, the line broadening is a direct result of $\mathrm{CC} 1 \Delta \mathrm{C} 223$-microtubule complex formation. Figure $4 \mathrm{c}$ shows the intensity ratios of crosspeaks taken from 3D HNCA spectra of ${ }^{15} \mathrm{~N},{ }^{13} \mathrm{C}$-labeled CC1 $\Delta \mathrm{C} 223$ in the presence and the absence of microtubules $\left(I_{\text {bound }} / I_{\text {free }}\right)$ per residue. A significant intensity decrease is observed in four regions, comprising residues ${ }^{23}$ RPVYYVQS $^{30},{ }^{45}$ FHSTPVLSPM $^{54}$, ${ }^{74}$ FSGSLKPG $^{83}$ and ${ }^{103}{ }^{\text {QWKECAVI }}{ }^{110}$ (Fig. 4c). Due to signal overlap, the region between residues 60 and 80 is not well covered. We found a clear correlation between the NMR-based microtubuleinteraction profile and the hydrophobicity pattern of $\mathrm{CC} 1 \Delta \mathrm{C} 223$, highlighting the role of hydrophobic interactions (Fig. 4d). The binding motifs are separated by stretches of mobile residues, presumably acting as linkers that are likely to retain a high degree of 
a

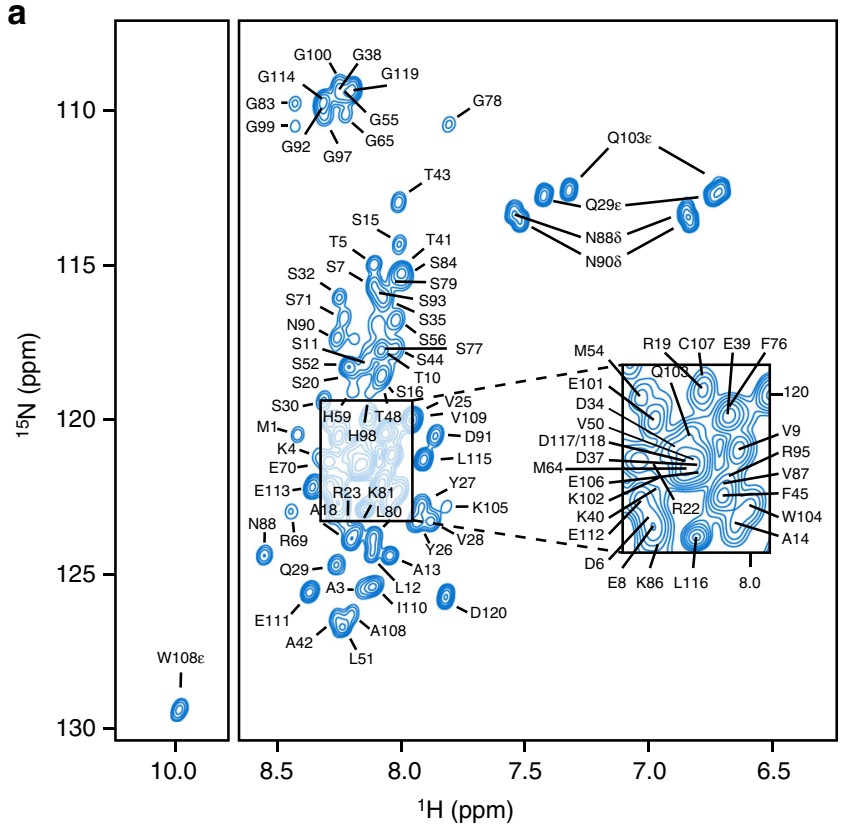

b

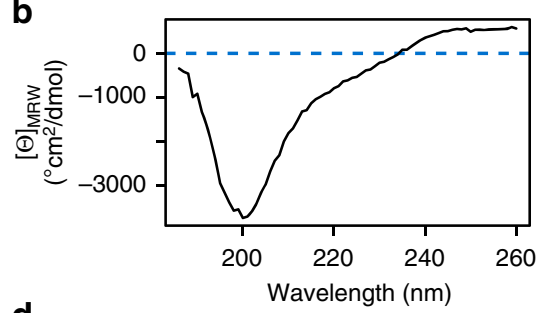

d
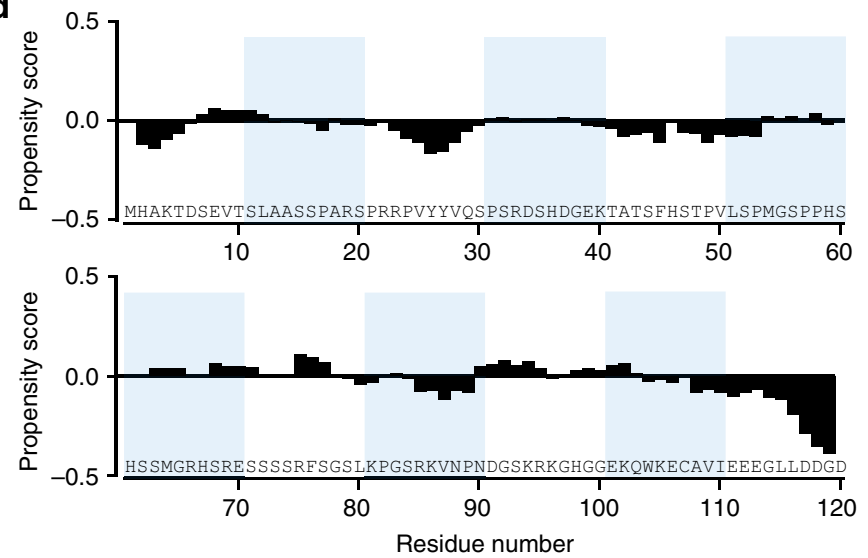

Fig. 3 Structural characteristics of the CC1 N-terminus. a Assigned ${ }^{1} \mathrm{H}-{ }^{15} \mathrm{~N}$ HSQC spectrum of ${ }^{15} \mathrm{~N}$-labeled CC1 $\Delta \mathrm{C} 223$ in solution. The low signal dispersion in the ${ }^{1} \mathrm{H}$ dimension is characteristic of an intrinsically disordered protein. $\mathbf{b}$ Circular dichroism (CD) spectrum of $6 \times \mathrm{His}-\mathrm{CC} 1 \Delta \mathrm{C} 223$ in solution supporting lack of clear structures in the protein. c Analytical ultracentrifugation at three different $\mathrm{CC} 1 \Delta \mathrm{C} 223$ concentrations showed a single size population at the approximate molecular weight of monomeric $\mathrm{CC} 1 \Delta \mathrm{C} 223$. The frictional coefficient of 1.7 is characteristic for elongated protein shapes. d Structural propensity plot of $\mathrm{CC} 1 \Delta \mathrm{C} 223$ calculated by $\mathrm{ncSPC} 27$ using $\Delta \delta \mathrm{C} \alpha, \Delta \delta \mathrm{C} \beta$ and $\Delta \delta \mathrm{C}^{\prime}$ secondary chemical shifts (Supplementary Fig. 4b-d). Propensity scores of 1 and -1 report on fully formed $\alpha$ - or $\beta$-structure, respectively

flexibility thus facilitating a highly dynamic interaction with microtubules. This binding behavior is reminiscent to that of $\mathrm{Tau}^{29}$, and the microtubule-binding regions of CC1 $1 \Delta 223$ also share remarkable similarities in hydrophobicity, size, and spacing with those of the microtubule-binding regions of Tau(201-320) (Fig. 4e).

Two tyrosine residues contribute to $\mathrm{CC1}$ microtubule binding. Microtubule binding of the four regions individually was investigated by saturation transfer difference (STD) NMR measurements (Supplementary Fig. 6a). The peptides CC1(16-38), CC1 (41-64), CC1(65-85) and a positive control peptide Tau (211-242) yielded strong STD intensities in the amide and aromatic regions of the ${ }^{1} \mathrm{H}$ spectrum (Supplementary Fig. 6b-e). No significant STD effects were observed for a negative control peptide, CC1(83-103), corresponding to the third poorly conserved linker region, and for the most C-terminal region CC1 (100-114) (Supplementary Fig. 6f-g). Targeting the N-terminal binding site, the exchange of ${ }^{26} \mathrm{YY}^{27}$ to alanine in a CC1YYAA (16-38) peptide resulted in a substantially reduced STD profile, corroborating a contribution of these aromatic rings to the interaction (Supplementary Fig. 6h). Indeed, the same mutation in $\mathrm{CC} 1 \Delta \mathrm{C} 223$ resulted in significantly reduced signal broadening of residues in the $\mathrm{N}$-terminal region, while the intensity ratios for the C-terminal part remained similar to the wild-type protein (Fig. 4f). Likewise, the mutated CC1 $\Delta \mathrm{C} 223$ bound to microtubules with a lower affinity compared to the wild-type sequence in microtubule spin down assays (Supplementary Fig. 6i-j), corroborating an important function of the two tyrosine residues in microtubule binding.

Mutation of CC1 impairs CESA movement. To assess how mutations in the two microtubule-binding tyrosine residues affect the function of CC1 in vivo, we mutated them to alanine in the full- length CC1 (CC1YYAA), fused it N-terminally with GFP, and transformed it into Arabidopsis thaliana $c c 1 c c 2$ mutant plants. The cc1cc2 mutant seedlings display reduced growth and crystalline cellulose content on salt-containing media ${ }^{5}$. These phenotypes were not restored in $c c 1 c c 2$ GFP-CC1YYAA seedlings when grown on salt-containing media as compared to controls (Fig. 5a-c).

Spinning-disc confocal microscopy showed GFP-CC1YYAA signals as distinct foci at the plasma membrane (Supplementary Movie 2) and within cytoplasmic compartments in dark-grown Arabidopsis hypocotyl cells, in accordance with reports on GFP$\mathrm{CC}^{5}$ (Supplementary Fig. 7a-c). GFP-CC1 co-localizes and migrates with tdTomato(tdT)-CESA6, which is an important subunit of the $\mathrm{CSC}^{30}$, at the plasma membrane ${ }^{5}$. Notably, the GFP-CC1YYAA also co-migrated with tdT-CESA6 at the plasma membrane on MS media without addition of salt (Supplementary Fig. 7a-b, d-e; Pearson correlation coefficient $r=0.74 \pm 0.06$; mean \pm S.D, six cells from six seedlings and three-independent experiments). However, in contrast to GFP-CC1, the migration of GFP-CC1YYAA was largely independent of cortical microtubules (mCherry (mCh)-TUA5 ${ }^{31}$; Fig. 5d-f). This indicates that reduced microtubule binding of GFP-CC1YYAA either directly affects the ability of CSCs to engage with microtubules, or that the microtubule array is mis-regulated and cannot fulfill its guiding function anymore.

Mutation of CC1 disrupts salt tolerance. To investigate whether the CC1YYAA can sustain microtubule and CSC function during salt exposure, we exposed seedlings to $200 \mathrm{mM}$ salt and recorded time series of microtubule (mCh-TUA5) and CC1 (GFP-CC1 or GFP-CC1YYAA) behavior (Supplementary Fig. 7f). The GFP-CC proteins (either GFP-CC1 or GFP-CC1YYAA) were considered as proxy for the CSC behavior because they co-localize and migrate together with tdT-CESA6. In agreement with ${ }^{5}$, the 

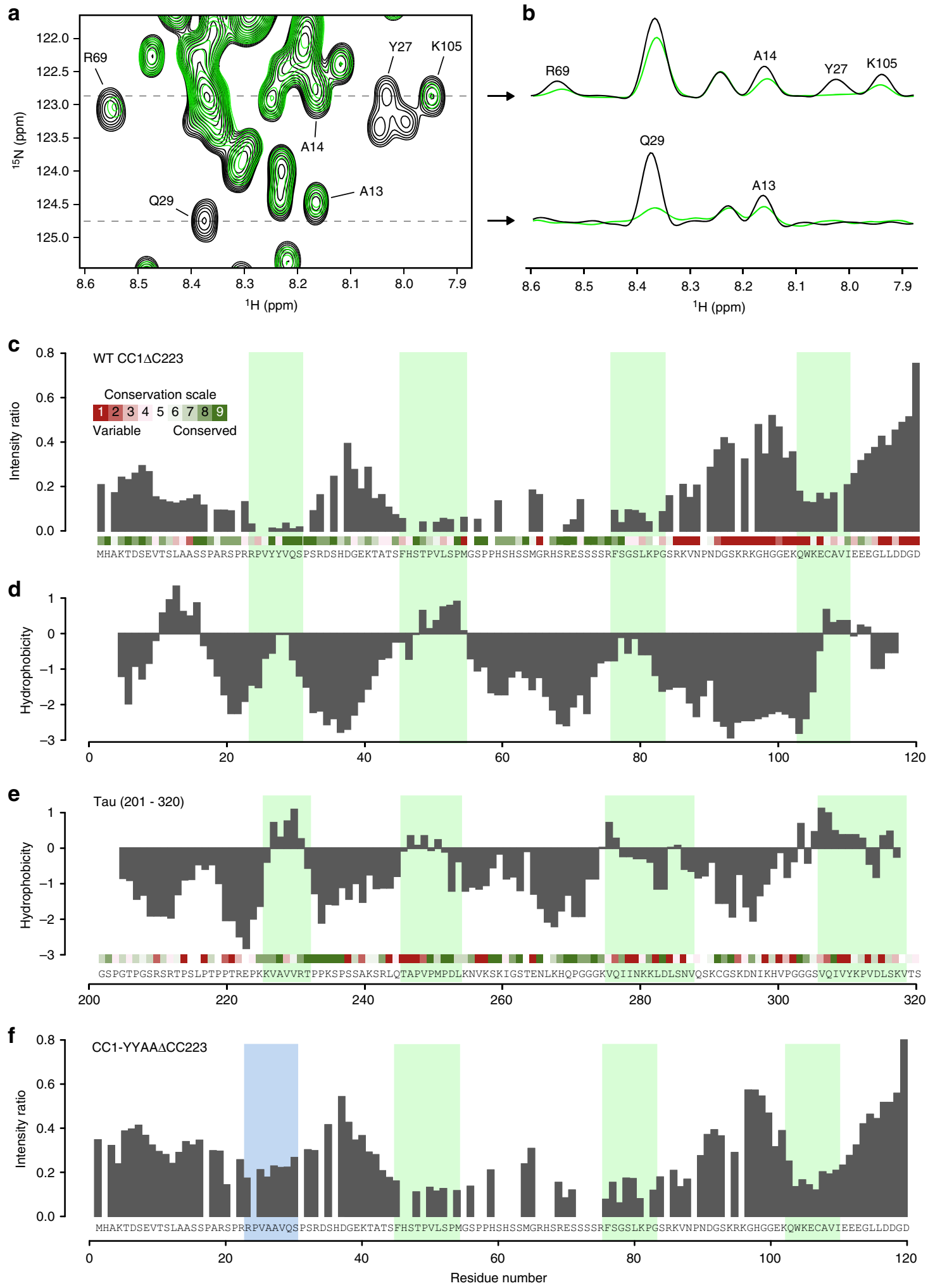

Fig. 4 The $\mathrm{N}$-terminus of $\mathrm{CC} 1$ binds to taxol-stabilized microtubules via short hydrophobic and conserved regions. a ${ }^{1} \mathrm{H}-{ }^{15} \mathrm{~N}$ HSQC spectrum of free $\mathrm{CC} 1 \Delta \mathrm{C} 223$ (black) and in the presence of equimolar taxol-stabilized microtubules (green). Selected residues are labeled. $\mathbf{b} \mathrm{F}_{2}$-cross sections, showing ${ }^{1} \mathrm{H}$-signals, taken along dotted lines in a at ${ }^{15} \mathrm{~N}$ frequencies 122.9 and $124.7 \mathrm{ppm}$. c Intensity ratio of free CC1 $1 \mathrm{C} 223 \mathrm{HNCA}$ signals and in complex with microtubules. Minima are highlighted with green bars. Site-specific evolutionary conservation calculated by CONSURF is plotted above the sequence in a color code (green = conserved, red = unconserved). $\mathbf{d}$ Hydrophobicity scores of CC1 $\Delta$ C223 according to the Kyte-Doolittle scale, calculated in a 5-residue window. e Hydrophobicity scores of Tau(201-320) according to the Kyte-Doolittle scale, calculated in a 5-residue window. Sequence conservation is plotted above the sequence like in c. Green bars highlight the interacting regions of Tau with microtubules as in ref. ${ }^{29}$. $\mathbf{f}$ Intensity ratio of free CC1YYAA $\triangle$ C223 HNCA signals and in complex with microtubules. Mutated N-terminal region highlighted with blue bar 


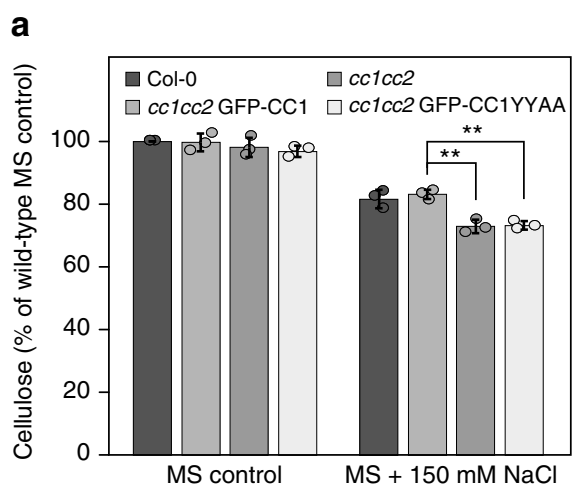

b

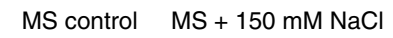

C
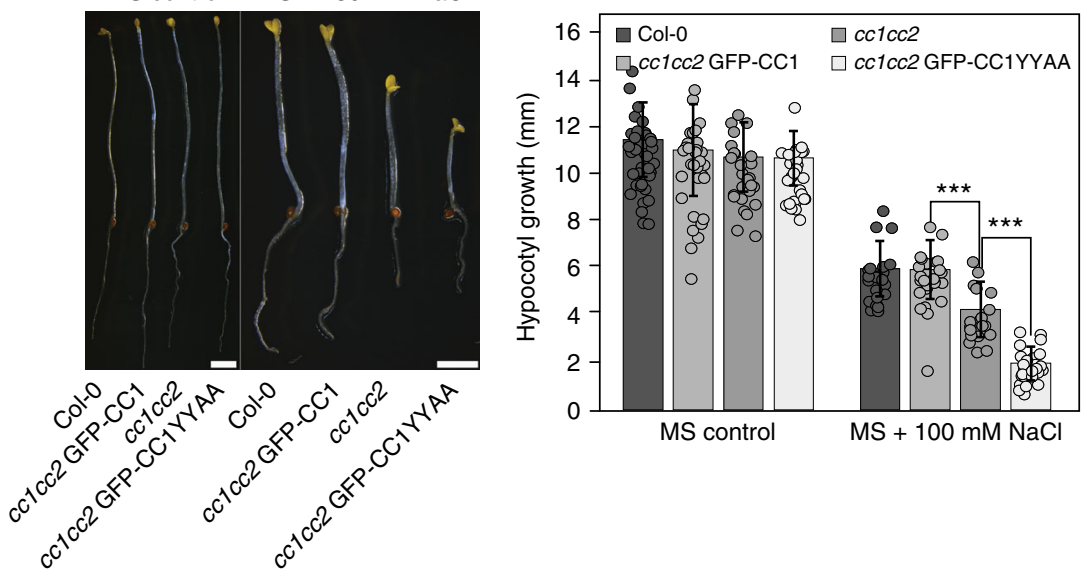

d

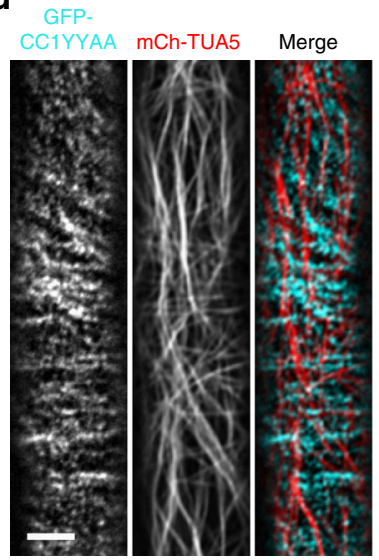

Single frames

g

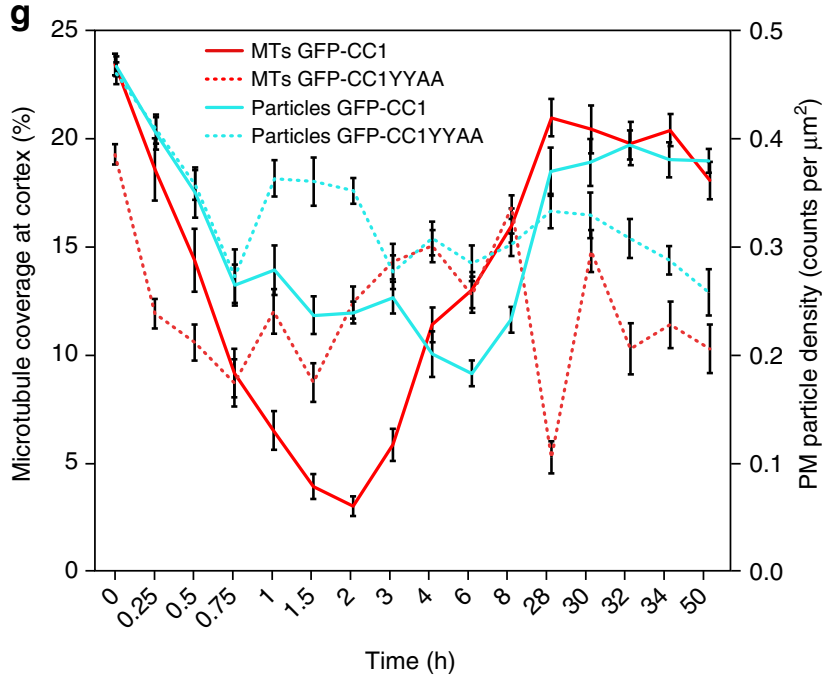

microtubule array and cellulose synthesis were restored within 28 $\mathrm{h}$ of salt exposure in the GFP-CC1-complemented $c c 1 c c 2$ seedlings (Fig. 5g). However, the cclcc2 GFP-CC1YYAAcomplemented seedlings largely mimicked the $c c 1 c c 2$ mutant seedlings and failed to restore the microtubule array and cellulose synthesis during the course of the experiment (Fig. 5g). Interestingly, while the $c c 1 c c 2$ GFP-CC1 line showed increased microtubule bundling of the salt-adjusted microtubule array, the cc1cc2 GFP-CC1YYAA cells failed to do so (Fig. 5h). Furthermore, the microtubule dynamics differed in the GFP-CC1 and

e
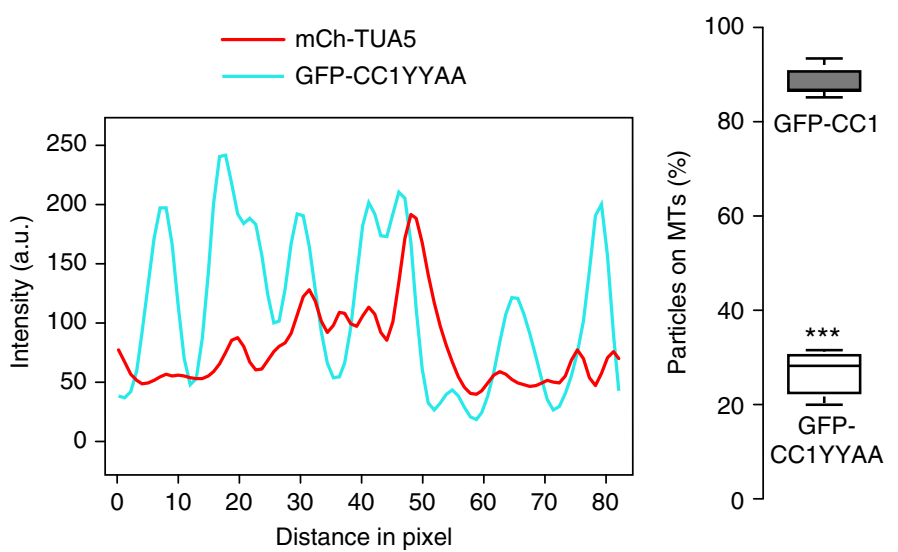

h

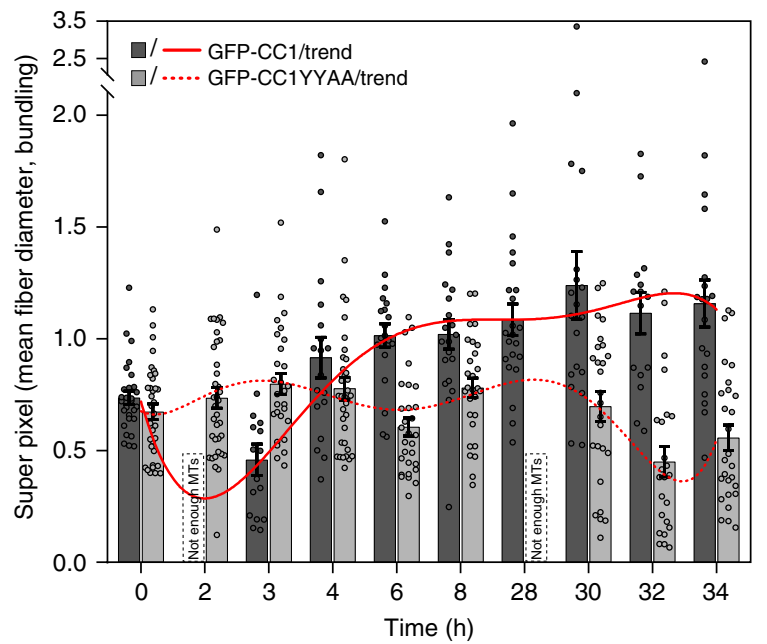

GFP-CC1YYAA cell lines (Supplementary Fig. 7g-h), indicating that the microtubule dynamics and bundling are key to build a salt-tolerant microtubule array. Hence, the YY-containing region of $\mathrm{CC} 1$ is necessary to sustain microtubule array organization and cellulose synthesis during salt stress.

\section{Discussion}

Abiotic stress, such as soil salinity, substantially impacts plant growth $^{32}$ and thus dramatically compromises global agricultural 
Fig. 5 Mutations in the first microtubule-binding region of CC1 impair salt tolerance of plants because of mis-regulated microtubule organization upon salt stress. a Cellulose levels in seedlings grown as in $\mathbf{b}$. Values are means \pm S.D. expressed as \% cellulose of wild-type seedlings grown on MS control media. Dots represent individual data points of the corresponding bars. $N \geq 3$ biological replicates with two technical replicates each from three-independent experiments. Welch's unpaired $t$-test; ${ }^{\star \star} p$-value $\leq 0.01$. b Seedlings germinated and grown for 2 days on MS plates and then transferred to either MS control plates or MS plates supplemented with $150 \mathrm{mM} \mathrm{NaCl}$ and grown for additional 5 days. Scale bar $=2$ mm. Please be aware that the images were stitched with Leica LAS X Life Science software. c Quantification of hypocotyl elongation of seedlings grown on MS plates for 3 days and then transferred to either MS control plates or MS plates supplemented with $100 \mathrm{mM} \mathrm{NaCl}$ and grown for additional 4 days. Dots represent individual data points of the corresponding bars. Values are mean \pm S.D., $n=30$ seedlings, 10 seedlings each per three-independent experiments. Welch's unpaired $t$-test; ${ }^{\star \star \star} p$-value $\leq$ 0.001. d GFP-CC1YYAA and mCh-TUA5 in dual-labeled 3-day-old cc1cc2 etiolated hypocotyls (left panels; single frame, right panels; time average projections). Scale bars $=5 \mu \mathrm{m}$. e Fluorescence intensity plot of GFP-CC1YYAA and tdT-CESA6 from transect in $\mathbf{d}$ along the depicted yellow line. Note that the GFP signal does not substantially correlate with the mCherry signal. $\mathbf{f}$ Quantification of GFP-CC1 and GFP-CC1YYAA fluorescent foci on cortical microtubules in a $50 \times 50$ pixel area of five individual time-lapse images, $n=5$ cells from 5 seedling and three independent experiments (box plots: Center lines show the medians; box limits indicate the 25th and 75th percentiles; whiskers extend to the minimum and maximum). Welch's unpaired $t$-test; ${ }^{\star \star \star} p$-value $\leq 0.001$. $\mathbf{g}$ Quantification of microtubule and GFP-CC (GFP-CC1 or GFP-CC1YYAA) coverage at the cell cortex and plasma membrane, respectively, after exposure of $c c 1 c c 2$ seedlings to $200 \mathrm{mM} \mathrm{NaCl}$ as in an experiment shown in Supplementary Fig. 7f. Time indicates time after salt exposure. Values are mean \pm S.E.M., $n=27$ cells from three seedlings per time point and three-independent experiments. Two-way ANOVA analysis of microtubule coverage; $p \leq 0.001$ (genotype), $p \leq 0.001$ (time), $p \leq 0.001$ (genotype $\times$ time). Two-way ANOVA analysis of GFP-CC protein density; $p \leq$ 0.01 (genotype), $p \leq 0.001$ (time), $p \leq 0.001$ (genotype $\times$ time). $\mathbf{h}$ Quantification of microtubule bundling after exposure of cc1cc2 GFP-CC1 /GFPCC1YYAA seedlings to $200 \mathrm{mM} \mathrm{NaCl}$ as in an experiment shown in Supplementary Fig. 7f. The salt-adjusted microtubule array in GFPCC1 seedlings shows increased bundling after exposure to salt while the array GFPCC1YYAA seedlings does not. Dots represent individual data points of the corresponding bars. Values are mean \pm S.E.M., $n=27$ cells from three seedlings per time point and three-independent experiments. Two-way ANOVA analysis of microtubule bundling (excluding T2 and T28); $p \leq 0.001$ (genotype), $p \leq 0.001$ (time), $p \leq 0.001$ (genotype $\times$ time)

productivity $\left(\sim 50-80 \%\right.$ loss in yield $\left.{ }^{33,34}\right)$. Unraveling molecular mechanisms that can be used to engineer plants for better stress tolerance is therefore of urgent importance. A potential target is the CC protein family that enables plants to sustain cellulose synthesis and the integrity of the cortical microtubule array during salt exposure ${ }^{5}$. Here, we describe how CC1 mediates the formation of a stress-stable cortical microtubule array. CC1 contains four motifs that transiently engage with microtubules and that enable microtubule polymerization and bundling, which facilitate microtubule reassembly after stress. The hydrophobic interactions of the CC1-microtubule complex could permit a more robust binding under conditions of high-ionic strength, corroborating the importance of the protein's function during salt stress. The two tyrosine residues in the most N-terminal microtubule-binding region of $\mathrm{CC} 1$ are key to the microtubule binding, both in vitro and in vivo. Mutations in these residues disrupted microtubule-guided CSC movement and led to failure in the generation of a stress-tolerant microtubule array.

Our results show that the microtubule binding characteristics of CC1 $1 \Delta 223$ are remarkably similar to that of Tau, while there is a characteristically different overall sequence architecture (Fig. 6a). Both Tau and CC1 $\Delta \mathrm{C} 223$ are intrinsically disordered proteins that can diffuse bidirectionally along the microtubule lattice ${ }^{10,29}$. While the typical PGGG-containing repeats of the Tau microtubule-binding domain (R1-R4) are not obvious from the $\mathrm{CC} 1$ sequence, the two proteins do contain four similarly spaced hydrophobic microtubule-binding regions (regions 1-4 in Fig. 6a, top). A sequence comparison of these four regions (Fig. 6a, bottom) reveals a surprisingly high number of identical or similar residues, implying evolutionary convergence of the microtubule-binding mechanism. A Tau fragment encompassing the four NMR-derived microtubule-binding regions (Tau (208-324); TauF4) joins microtubules wall-to-wall similar to that of CC $1 \Delta \mathrm{C} 223^{35}$. In-depth NMR studies using TauF4 $4^{36}$, and cryoEM studies on full-length $\mathrm{Tau}^{8}$, proposed that microtubulebound Tau spans multiple tubulin heterodimers along the microtubule principal axis. The equivalence of cross-linked positions on $\alpha$-tubulin ${ }^{22}$ between $C C 1 \Delta \mathrm{C} 223$ and Tau and the longitudinal microtubule decoration of $\mathrm{CC} 1 \Delta \mathrm{C} 223$ in the goldlabeling experiments could suggest a similar interaction of CC1 $1 \Delta 223$ with microtubules. Comparable to the effects of tyrosine to alanine mutations in $\mathrm{CC} 1$, disease-related mutations in Tau cause distinct defects in microtubule organization ${ }^{37}$. Furthermore, Tau-depleted rat neurons exhibit a reduction of microtubule dynamics ${ }^{38}$, similar to what we observed for the misregulated microtubule array in both the $c c 1 c c 2$ knockout ${ }^{5}$ and the CC1-YYAA complemented mutant. Further functional and structural analogies between Tau and $\mathrm{CC} 1$ are reflected in the fact that both Tau and CC1 are relevant for the organism to function during stress conditions; CC1 promotes cellulose synthesis during salt stress ${ }^{5}$; whereas, Tau has emerged as a key regulator of stressinduced brain pathology in mice and oxidative stress in cultured fibroblasts ${ }^{39,40}$.

While there are functional and structural analogies between $\mathrm{CC} 1$ and Tau, other features of the two proteins are clearly different. For example, $\mathrm{CC} 1$ contains a putative transmembrane and an apoplastic domain ${ }^{5}$, whereas Tau is a cytoplasmic protein with an $\mathrm{N}$-terminal projection domain that regulates microtubule spacing (Fig. 6a) ${ }^{41}$. Moreover, CC1 is a core component of the CSC, which is primarily localized on bundled cortical microtubules and its movement is guided by cortical microtubules in plant interphase cells (Fig. 6b) ${ }^{3}$. In this setting, the CC1 microtubule-binding regions interact with tubulin dimers in one, or multiple microtubules, and the microtubule-binding motif that contains the two tyrosine residues essential for stress-stable microtubule array formation is most distal to the plasma membrane. Given the local environment of $\mathrm{CC} 1$, i.e. being part of the CSC and integral to the plasma membrane, this distal motif might be the most prominently exposed of the four microtubule-binding motifs and therefore also most prominent in the microtubule engagement. Notably, the microtubule arrays have different design principles in animal and plant cells. The centrosomecoordinated microtubules in animal cells typically radiate from the cell center towards the periphery, while growing plant cells have a cortical microtubule array, with evenly distributed microtubules along the cell cortex ${ }^{2}$. We speculate that the differences in the protein domain architecture and localization of Tau and CC1 coincide with this differential microtubule array organization. In this context, the $\mathrm{CC} 1$ proteins are superbly situated to modulate microtubule dynamics and bundling to optimize cellulose synthesis under different environmental conditions (Fig. 6b). Engineering the microtubule-binding properties 
a $\mathrm{CC} 1$

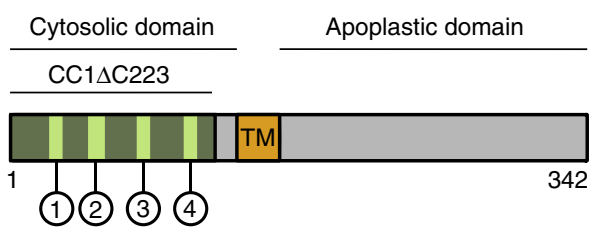

Tau

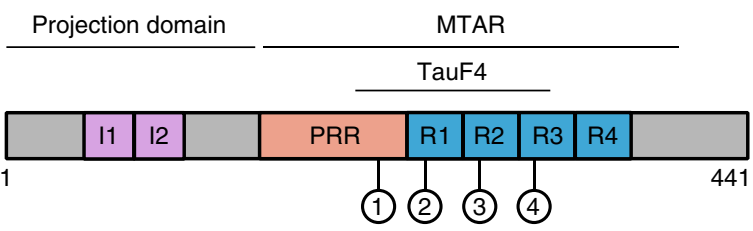

2

3

FHSTPVLSPM LQTAPVPMPDI

b

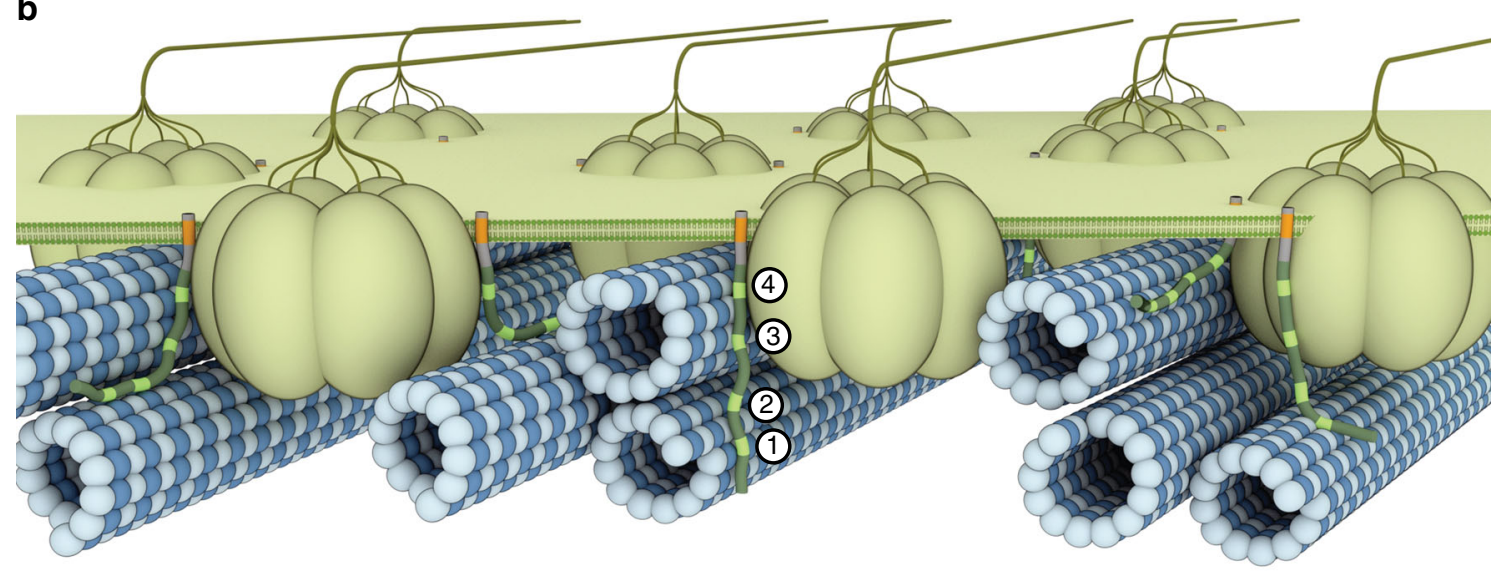

Fig. 6 Cartoon overview of the CC1-microtubule interaction and its similarity to Tau despite sequential differences. a Cartoon representation of the CC1 and hTau40 domain architecture. CC1 is composed of a cytosolic N-Terminus, transmembrane domain (TM) and an apoplastic C-terminal domain. hTau40 represents the longest isoform in humans containing two N-terminal inserts $(11,12)$ in the projection domain, a polyproline region (PRR) and four imperfect repeats (R1-R4) in the microtubule assembly region (MTAR). The position of the four respective microtubule-binding regions are marked and highlighted green in CC1. The amino acid sequences below compare the NMR-derived microtubule-binding regions of CC1 and Tau. Identical (green) and similar (orange; score of $\geq 0$ in the BLOSUM62 matrix) amino acids are highlighted. $\mathbf{b}$ CC1 localization in its cellular context as part of the cellulose synthase complex (CSC). While the CSCs migrate along cortical microtubules during cellulose production, CC1 is involved in microtubule array organization via its cytosolic N-terminus. Similar to the Tau binding behavior, the CC1-microtubule interaction is dynamic and the microtubule-binding motifs (green) are potentially able to bind several tubulin dimers, distributed over one or several microtubules, thereby affecting microtubule bundling or dynamics. The individual components of the cartoon representation are drawn to scale, except for CC1 thickness and omission of its apoplastic domain. Membrane association and length of $\mathrm{CC} 1$, as well as the microtubule diameter, determine possible interaction modes

of this domain, perhaps by design principles of Tau, might improve cellulose synthesis and thus biomass production on saltaffected lands.

\section{Methods}

Plant material and growth. T-DNA insertion lines $c c 1$ (SAIL 838 F07) and $c c 2$ (GK_511F01) and double mutant lines $c c 1 c c 2$ were described earlier ${ }^{5}$. Primers used to screen for homozygous insertion lines can be found in Supplementary Table 1 (primers 1-7).

For genotyping the $c c 1$ mutant, $c c 1 \mathrm{LP}+c c 1 \mathrm{RP}$ were combined for wild-type PCRs, for insertion PCRs $c c 1$ RP + LB SAIL were combined. For genotyping the $c c 2$ mutant, $c c 2 \mathrm{LP}+c c 2 \mathrm{RP}$ were combined for wild-type PCRs, for insertion PCRs $c c 2$ insert $\mathrm{fw}+08409$ GABI Insert were combined. To check for the insertion of the YY to AA mutated version of GFP-CC1, plants were genotyped with primers listed in Supplementary Table 1 (primers 8-9).

The marker lines mCherry-TUA $5^{31}$ and tdTomato-CesA $6^{30}$ have been described previously. Arabidopsis plants were grown as described ${ }^{30,42}$. The lines $c c 1 c c 2$ GFP-CC1 and $c c 1 c c 2$ GFP-CC1 $1 \mathrm{~N} 120$ were described previously ${ }^{5}$. Seedlings were grown on control (MS media $+1 \%$ sucrose) and plates supplemented with $2 \mathrm{nM}$ isoxaben or $300 \mathrm{nM}$ oryzalin and hypocotyl elongation was quantified after 4 and 7 days of growth, respectively. For salt treatments, seeds germinated and grown for 3 days on MS media $+1 \%$ sucrose were transferred to MS plates containing $100 \mathrm{mM} \mathrm{NaCl}+1 \%$ sucrose. After 4 additional days of growth, hypocotyl elongation on salt media was measured. Plants were always randomly distributed in the growth/treatment chambers.

Constructs. To mutate ${ }^{26} \mathrm{YY}^{27}$ in the $\mathrm{CC} 1$ sequence to alanine residues, pENTR_CC1 ${ }^{5}$ was linearized with ApaI and BamH1. Two mutation PCRs with primers listed in Supplementary Table 1 (primers 10-13) and pENTR_CC1 as a template were performed.
The two overlapping PCR products were purified and subsequently inserted into the linearized vector backbone using the Gibson cloning method ${ }^{43}$. The resulting mutated pENTR-CC1YYtoAA was subsequently inserted into UBNGFPpDEST $^{43,44}$ by performing LR reactions of the Gateway cloning system (Invitrogen, USA).

For heterologous protein expression of $\mathrm{CC} 1 \Delta \mathrm{C} 223$ with a hexa histidine-tag in E. coli, the construct pDEST17CC1 $\triangle \mathrm{C} 223$ was used ${ }^{5}$. To obtain the hexa histidinetagged, mutated ${ }^{26} \mathrm{YY}^{27}$ to ${ }^{26} \mathrm{AA}^{27}$ version of CC1 $\triangle \mathrm{C} 223$, pENTRCC $1 \Delta \mathrm{C} 223^{5}$ was linearized with ApaI and BamH1. Two mutation PCRs were performed using pENTRCC1 $\triangle \mathrm{C} 223$ as a template and the primers "mut general fw", "YY to AA rev", "YY to AA" fw and "mut general rev" as described above. The two overlapping PCR products were purified and subsequently inserted into the linearized vector backbone using the Gibson cloning method. The resulting pENTR-CC1 $\triangle$ C223YYAA was subsequently inserted into the Gateway ${ }^{\circledR}$ pDEST $^{\mathrm{mm}} 17$ Vector (Invitrogen, USA) by performing LR reactions.

For the production of NMR-samples from an ineffective pETM11

His_Sumo_CC1 $1 \mathrm{C} 223$ construct the Sumo part was removed and a $3 \mathrm{C}$ site was introduced. That construct and two mutants were made by a modified

QuickChange protocol, introducing mutation sites via primer amplification (primers 14-17; Supplementary Table 1) of the whole vector by KOD-polymerase (Novagen, Merck, Germany) and subsequent digest of parental vector by DpnI (fast digest, Thermo Fisher Scientific Inc., USA). The setup was transformed into Giga cells (Novagen, Merck, Germany) for plasmid preparation and sequencing (Source Bioscience, UK).

Representative image acquisition of seedlings. Representative images of seedlings grown on plates with a diversity of drugs were acquired with a Leica M205 FA or ZEISS Axio Zoom.V16 microscope. Before imaging, the seedlings were transferred to fresh MS plates. The stitching function of Leica LAS X Life Science software was used when seedling did not fit into one image at lowest magnification. 
Heterologous protein expression. 6xHis-tagged $\mathrm{CC} 1 \Delta \mathrm{C} 223$ and 6xHis-tagged $\mathrm{CC} 1 \triangle \mathrm{C} 223 Y_{Y A A}$ (using the Gateway ${ }^{\oplus}$ pDEST 17 Vector (Invitrogen, USA) were expressed in Rosetta2 (DE3) pLysS E. coli Cells (Merck Millipore, Germany). A starter culture was grown overnight at $28^{\circ} \mathrm{C}$ and used to inoculate the main cultures. Cultures were grown at $37^{\circ} \mathrm{C}$ until an OD600 $\sim 0.6$ was reached and protein expression was induced by addition of isopropyl $\beta$-D-1-thiogalactopyranoside (IPTG) at a final concentration of $1 \mathrm{mM}$. Cells were collected after $3 \mathrm{~h}$ by centrifugation, washed in $150 \mathrm{mM} \mathrm{NaCl}$ and resuspended in lysis buffer (50 mM Tris$\mathrm{HCl}, 200 \mathrm{mM} \mathrm{NaCl}, 20 \mathrm{mM}$ imidazole, $\mathrm{pH}$ 7.4). Cell lysates were prepared by passing the solution through an Microfluidics M-110P Homogenizer (Microfluidics Corp., USA) at 22,000 psi for four times. Cellular debris was spun down, supernatant was collected and filtered through a $0.2 \mu \mathrm{m}$ filter. Recombinant proteins were purified using Ni Sepharose ${ }^{\text {tw }}$ High Performance HisTrap ${ }^{\text {mt }}$ HP columns (GE Healthcare Life Sciences, USA) and an ÄKTA pure 25L (GE Healthcare Life Sciences, USA) equipped with a $50 \mathrm{ml}$ Superloop. Buffers for protein purification were prepared as follows: Buffer A: $50 \mathrm{mM}$ Tris- $\mathrm{HCl}(\mathrm{pH} 7.4), 200 \mathrm{mM}$ NaCl; Buffer B: $50 \mathrm{mM}$ Tris- $\mathrm{HCl}$ (pH 7.4), $200 \mathrm{mM} \mathrm{NaCl}, 500 \mathrm{mM}$ Imidazole. Sample application onto the column was performed at $1 \mathrm{ml} / \mathrm{min}$ with $92 \% \mathrm{~A}$ and $8 \% \mathrm{~B}$. The column was washed stepwise at $1.5 \mathrm{ml} / \mathrm{min}$ as follows: 20 column volumes (CV) $92 \% \mathrm{~A}$ and $8 \%$ B, 6 CV $80 \%$ A and $20 \%$ B, 6 CV $65 \%$ A and $35 \%$ B. Final protein sample was eluted at $1.5 \mathrm{ml} / \mathrm{min}$ for $10 \mathrm{CV}$ with $100 \% \mathrm{~B}$ in upflow mode. Samples were collected in $2 \mathrm{ml}$ fractions. Fractions enriched with protein were combined and gel filtered to remove imidazole using PD-10 Desalting Columns (GE Healthcare, USA) according to the gravity protocol in the manual. The column was equilibrated with $50 \mathrm{mM}$ Tris- $\mathrm{HCl}$ (pH 7.4), $200 \mathrm{mM} \mathrm{NaCl}$. In a final step, proteins were concentrated at $12^{\circ} \mathrm{C}$ and $3000 \times g$ using Macrosep ${ }^{\circledast}$ Advance Centrifugal Devices with a $3 \mathrm{~K}$ cutoff (Pall Corporation, USA). Proteins were snap frozen and stored at $-80^{\circ} \mathrm{C}$ until further use.

For NMR-scale production of CC1 $\triangle \mathrm{C} 223$ and CC1 $\triangle \mathrm{C} 223 \mathrm{YYAA}$, pETM11 HisCC1 $\Delta \mathrm{C} 223$ (KanaR) or mutants and the helper plasmid pBAD-б32 (I54N) (AmpR) were co- transformed into the Escherichia coli strain BL21(DE3) star (Thermo Fisher Scientific Inc., USA). $\sigma 32-154 \mathrm{~N}$ expression was induced at an OD of 0.6 with $0.2 \% \mathrm{~L}$-arabinose for $2 \mathrm{~h}$ on LB medium, followed by the induction of His-CC1 $\triangle \mathrm{C} 223$ with $1 \mathrm{mM}$ IPTG on minimal medium M9 with ${ }^{13} \mathrm{C}$ glucose and ${ }^{15} \mathrm{~N} \mathrm{NH}_{4} \mathrm{Cl}$ for NMR purposes. Cells were collected by centrifugation after additional $5 \mathrm{~h}$ at $37^{\circ} \mathrm{C}$. His-CC1 $\Delta \mathrm{C} 223$ was purified by metal chelate chromatography. The His-tag was cleaved off overnight with 3C/PreScission Protease at $10^{\circ} \mathrm{C}$. The cleaved tag and the protein were separated by gel filtration including the exchange of the buffer to $20 \mathrm{mM}$ Tris- $\mathrm{HCl}, 200 \mathrm{mM} \mathrm{NaCl}(\mathrm{pH}$ 7.4). Final samples had a concentration in the range of $1-6 \mathrm{mg} / \mathrm{ml}(70-500 \mu \mathrm{M})$ containing $0.02 \%$ sodium azide and protease Inhibitor (cOmplete, EDTA-free; Roche, $\mathrm{CH}$ ). Extinction coefficients of proteins were determined with ProtParam ${ }^{45}$.

\section{Cross-linking and tandem mass spectrometry. $6 \mathrm{xHis}-\mathrm{CC} 1 \Delta \mathrm{C} 223$ was purified as} described above but $50 \mathrm{mM}$ Tris- $\mathrm{HCl}(\mathrm{pH}$ 7.4) was exchanged for $50 \mathrm{mM}$ sodium phosphate buffer ( $\mathrm{pH}$ 7.0). The protein was diluted in the same buffer to a concentration of $1 \mathrm{mg} / \mathrm{ml}$. Tubulin was solubilized to a final concentration of $1 \mathrm{mg} / \mathrm{ml}$ in $50 \mathrm{mM}$ sodium phosphate buffer (pH 7.0). $100 \mu \mathrm{l}$ tubulin and $72 \mu \mathrm{l} 6 \mathrm{xHis}-$ $\mathrm{CC} 1 \Delta \mathrm{C} 223$ were mixed with $28 \mu \mathrm{l}$ of $50 \mathrm{mM}$ sodium phosphate buffer (pH 7.0). Accordingly, the final concentration of both proteins in the reaction mixture was $40 \mu \mathrm{M}$. Cross-linking was initiated by adding $10 \mu \mathrm{l}$ 1-ethyl-3-(3-dimethylaminopropyl)carbodiimide hydrochloride (EDC) $(10 \mathrm{mg} / \mathrm{ml}$ in water). The reaction was incubated at RT on a rotating device $(600 \mathrm{rpm})$ for $2 \mathrm{~h}$. Free EDC was removed by gel filtration using PD midiTrap G-25 columns (GE Healthcare, USA) according to the spin protocol in the manual. The column was equilibrated with $50 \mathrm{mM}$ sodium phosphate buffer ( $\mathrm{pH} 7.0$ ) and $200 \mathrm{mM} \mathrm{NaCl} .50 \mu \mathrm{l}$ of the EDC sample was subjected to in solution digestion with trypsin and $75 \mu \mathrm{l}$ was used for SDS-PAGE. In solution digestion with trypsin ("Trypsin Gold, Mass Spectrometry Grade", Promega, USA) was performed as described by ${ }^{46}$. Deviating from the protocol, no alkylation of cysteines was performed $(6 \mathrm{xHis}-\mathrm{CC} 1 \Delta \mathrm{C} 223$ only consists of one cysteine at the C-terminus).

For in gel digestion, the sample was divided into three aliquots and loaded on a gradient protein gel (NuPAGE ${ }^{\mathrm{m}} 4-12 \%$ Bis-Tris Protein Gels, $1.5 \mathrm{~mm}$, 10-well, Thermo Fisher Scientific). SDS-PAGE was performed as described by ref. ${ }^{47}$. The bands corresponding to the molecular weight of tubulin cross-linked to 6xHis$\mathrm{CC} 1 \Delta \mathrm{C} 223$ were excised and combined. In-gel digestion of the cut bands was performed as described by ref. ${ }^{48}$. Again, no alkylation of cysteines was performed. LC/MS/MS analysis of the cross-linked samples was performed on an Orbitrap Fusion $^{\text {me }}$ Lumos $^{\text {mx }}$ Tribrid ${ }^{\mathrm{mt}}$ Mass Spectrometer (Thermo Fisher Scientific) fitted with a nanoflow HPLC (Ultimate 3000 RSLC, Dionex). The nano-LC system was equipped with an Acclaim Pepmap nano-trap column (Dionex - C18, $100 \AA$, $75 \mu \mathrm{m} \times 2 \mathrm{~cm}$ ) and an Acclaim Pepmap RSLC analytical column (Dionex - C18, $100 \AA, 75 \mu \mathrm{m} \times 50 \mathrm{~cm}$ ). The samples were loaded on the trap column with an isocratic flow of $5 \mu \mathrm{l} / \mathrm{min}$ of $3 \% \mathrm{CH}_{3} \mathrm{CN}$ containing $0.1 \%$ formic acid for $5 \mathrm{~min}$ before it was switched in-line with the analytical column. Samples were eluted with $0.1 \%(\mathrm{v} / \mathrm{v})$ formic acid (A) and $100 \% \mathrm{CH}_{3} \mathrm{CN} / 0.1 \%$ formic acid (v/v) (B). Solvents were applied with the following gradient: $3 \%$ B to $12 \%$ B for 1 min, $12 \%$ B to $35 \%$ B in $43 \mathrm{~min}, 35 \% \mathrm{~B}$ to $80 \% \mathrm{~B}$ in $2 \mathrm{~min}$. The MS system was operated in positive ion mode at a resolution of 120,000 in full scan mode using data-dependent acquisition (DDA). The MS2 was operated in HCD mode with a resolution of 30,000, AGC target of 50,000 and Activation Q of 0.25 for ions above 50,000 with a charge state between 3 and 8 . Raw data were converted to mgf or mzML format with MSconvert ${ }^{49}$ with peak picking enabled. A sequence database comprising the $\mathrm{CC} 1$ protein (including N-terminal 6xHis), tubulin beta chain (TBB_PIG: https://www. uniprot.org/uniprot/P02554) and tubulin alpha-1A chain (TBA1A_PIG: https:// www.uniprot.org/uniprot/P02550) was employed for all queries. For analysis with StavroX, the four mgf files where combined into a single file with an automated batch file from PROTEIN METRICS.

For the initial identification of cross-linked peptides, four different tools were used: Crux $^{21}$, Spectrum Identification Machine (SIM-XL) ${ }^{20}$, pLink $^{19}$ StavroX ${ }^{18}$. All parameters and settings for the tools can be found in Supplementary Methods section. Spectra identified with Crux were visualized and annotated using mMass (ver. 5.5.0) ${ }^{50}$

Finally, all identified spectra corresponding to cross-linked peptides from the four different tools were manually inspected to ensure assignment of major product ions. The mass spectrometry proteomics data have been deposited to the ProteomeXchange Consortium via the PRIDE $^{51}$ partner repository with the dataset identifier PXD009260.

Microtubule bundling assay and TEM. A total of $33 \mu \mathrm{L}$ of $6 \times \mathrm{xHis}-\mathrm{CC} 1 \Delta \mathrm{C} 223$ (purified as described above in $50 \mathrm{mM}$ Tris- $\mathrm{HCl}(\mathrm{pH} 7.4), 200 \mathrm{mM} \mathrm{NaCl}$ ) in various concentrations were added on ice to $30 \mu \mathrm{L}$ of porcine tubulin (Cytoskeleton \#240-A) ( $4 \mathrm{mg} / \mathrm{ml}$ ) in BRB80 (80 mM PIPES, $1 \mathrm{mM} \mathrm{MgCl}$, $1 \mathrm{mM} \mathrm{EGTA,} \mathrm{pH} 6.8$ adjusted with $\mathrm{KOH})+1 \mathrm{mM}$ GTP (G8877 Sigma). $10 \mu \mathrm{L}$ of BRB80 Cushion (80 mM PIPES, $1 \mathrm{mM} \mathrm{MgCl}$, 1 mM EGTA, 60\% glycerol, pH 6.8 adjusted with $\mathrm{KOH})$ were added in a last step. $6 \times \mathrm{xHis}-\mathrm{CC} 1 \Delta \mathrm{C} 223$ concentrations were ranging from 1.7 to $5.1 \mu \mathrm{M}$. The mixture was incubated at room temperature for $20 \mathrm{~min}$ to allow microtubules to polymerize in the presence of $6 \mathrm{xHis}-\mathrm{CC} 1 \Delta \mathrm{C} 223$. As controls, the highest concentration of $6 \mathrm{xHis}-\mathrm{CC} 1 \Delta \mathrm{C} 223(5.1 \mu \mathrm{M})$ was replaced with an equal amount of BSA (Sigma), or with $50 \mathrm{mM}$ Tris- $\mathrm{HCl}$ (pH 7.4), $200 \mathrm{mM} \mathrm{NaCl}$ buffer only. Microtubules were pelleted by centrifugation at 30,000 $\times g$ and room temperature for $30 \mathrm{~min}$, and supernatant was discarded. Microtubules were resuspended in $100 \mu \mathrm{L}$ BRB80 with $5 \mu \mathrm{M}$ taxol. $10 \mu \mathrm{L}$ of sample was applied to copper grids (Gilder) coated with $0.3 \%$ formvar (Electron Microscopy Sciences) and absorbed for $30 \mathrm{~s}$, washed once quickly with $\mathrm{dH}_{2} \mathrm{O}$, then stained with $10 \mu \mathrm{L}$ of $1 \%$ aqueous uranyl acetate solution for $60 \mathrm{~s}$, rinsed once quickly with $\mathrm{dH}_{2} \mathrm{O}$, and dried. Samples were imaged on a Philips CM120 BioTWIN transmission electron microscope equipped with a Gatan MultiScan 791 CCD camera and a tungsten filament at an accelerating voltage of $120 \mathrm{kV}$ or a Tecnai G2 Spirit TEM equipped with an FEI Eagle 4K-HS CCD camera and a LaB6 filament at an accelerating voltage of $120 \mathrm{kV}$. Microtubule bundling was assessed in images by counting the number of microtubules per bundle (degree of bundling) and the percentage of microtubules in images that were incorporated into bundles.

Gold labeling and TEM of microtubule-associated CC1. Microtubules were polymerized in the presence of $\mathrm{CC} 1$ as described above, but the pelleted microtubules were resuspended in BRB80 without EGTA plus $5 \mu \mathrm{M}$ taxol. $5 \mathrm{~nm}$ gold functionalized with a Ni-NTA group (Nanoprobes \#2082) was added to the CC1microtubule mixture to a final concentration of $1 / 10$ and incubated for $30 \mathrm{~min}$ at room temperature. To remove unbound gold, the CC1-microtubule mixture was applied to a $3 \mathrm{k}$ spin column (Pall Naonsep) and centrifuged in $30 \mathrm{~s}$ intervals at $600 \times g$ until most of the liquid had flowed through the column, but the microtubules were not dried. The column was rinsed by applying $50 \mu \mathrm{L}$ BRB80 without EGTA plus $5 \mu \mathrm{M}$ taxol using the same method. The microtubules in buffer that remained on the column were absorbed onto formvar coated grids, negatively stained, and imaged as described above. Gold distribution along microtubules was quantified using Fiji ${ }^{52-54}$

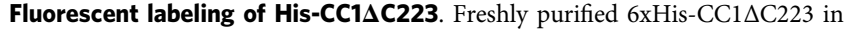
$50 \mathrm{mM}$ Tris- $\mathrm{HCl}$ (pH 7.25), $200 \mathrm{mM} \mathrm{NaCl}$ at a concentration of $60 \mu \mathrm{M}$ was used (see above for purification details). CF488A CF Dye Maleimide (Biotium, Inc., USA) was diluted in anhydrous DMSO to a concentration of $10 \mathrm{mM}$. The dye was added to the protein sample under constant shaking $(650 \mathrm{rpm})$ in a 10X molar excess. Samples were incubated in the dark $/ 650 \mathrm{rpm}$ at RT for $2 \mathrm{~h}$. The protein was again loaded onto a Ni Sepharose ${ }^{\text {tw }}$ High Performance HisTrap ${ }^{\text {me }}$ HP column (GE Healthcare Life Sciences, USA) and washed with $50 \mathrm{mM}$ Tris-HCl (pH 7.4), $200 \mathrm{mM} \mathrm{NaCl}$ until the flow through was clear and unbound dye removed. The labeled protein was then eluted with $50 \mathrm{mM}$ Tris- $\mathrm{HCl}(\mathrm{pH} \mathrm{7.4)}, 200 \mathrm{mM} \mathrm{NaCl}$, $250 \mathrm{mM}$ imidazole. To remove imidazole and the last traces of unbound dye, the protein was dialyzed in Spectra/Por ${ }^{\circledR}$ Dialysis Tubing (3500 molecular weight cutoff) (Spectrum Laboratories, Inc., USA) overnight against $50 \mathrm{mM}$ Tris- $\mathrm{HCl}$ (pH 7.4), $200 \mathrm{mM} \mathrm{NaCl}$. The protein was concentrated at $12^{\circ} \mathrm{C}$ and $3,000 \times g$ using a Macrosep ${ }^{\circledR}$ Advance Centrifugal Devices with a $3 \mathrm{~K}$ cutoff (Pall Corporation, USA). Proteins were snap frozen and stored at $-80{ }^{\circ} \mathrm{C}$ until further use.

The concentration of the labeled protein was calculated using the following equation:

[conjugate] $(\mathrm{mg} / \mathrm{mL})=\{[\mathrm{A} 280-(\mathrm{A} 490 \times \mathrm{CF})] / \mathcal{\varepsilon}\} \times \mathrm{df} ; \mathrm{CF}=$ correction factor $=0.1$ for CF $488 \mathrm{~A} ; \varepsilon=$ molar extinction coefficient of $6 \mathrm{xHis}-\mathrm{CC} 1 \Delta \mathrm{C} 223$ in $\mathrm{mg} / \mathrm{mL}=0.803$; $\mathrm{df}=$ dilution factor. 
The degree of labeling (DOL) was calculated using the following equation: $\mathrm{DOL}=(\mathrm{A} 490 \times \mathrm{Mwt} \times \mathrm{df}) /(\varepsilon \times[$ conjugate $]) ; \mathrm{Mwt}=$ molecular weight of $6 \mathrm{xHis}-$ $\mathrm{CC} 1 \Delta \mathrm{C} 223=16,122 \mathrm{Da} ; \mathrm{df}=$ dilution factor; $\varepsilon=$ molar extinction coefficient of CF488A $(70,000)$.

Microtubule diffusion assay. Flow cells were made from two glass cover slips and $1 \mathrm{~mm}$ wide stripes of double-sided sticky tape (tesa, Germany). General handling was performed as described earlier ${ }^{26}$. Briefly, Rhodamine-labeled tubulin (Cytoskeleton, Inc., USA) was mixed in a 1:20 ration with unlabeled tubulin (Cytoskeleton, Inc., USA). $4 \mathrm{mg} / \mathrm{ml}$ of the mixture were polymerized to microtubules, stabilized with taxol and bound onto an anti $\beta$-tubulin antibody (1:200 dilution; Sigma Monoclonal Anti-ß-Tubulin \#T7816) coated imagining channel as described earlier ${ }^{26,55}$. CF488A-labeled $\mathrm{CC} 1 \triangle \mathrm{C} 223(\mathrm{DOL}=0.11)$ was mixed 1:4 with unlabeled $\mathrm{CC} 1 \Delta \mathrm{C} 223$, was then injected into the imaging channel and incubated for 30 s. Unbound protein was washed out with antifade solution ${ }^{26}$. To image the motility of $\mathrm{CC} 1 \Delta \mathrm{C} 223$ proteins, objective-type total internal reflection fluorescence (TIRF) microscopy was carried out on an inverted AxioObserver equipped with a TIRFslider system (both from Zeiss, Götttingen, Germany). The slider was fiber-coupled to a $488 \mathrm{~nm}$ diode laser (Stradus 488-50, Vortran Laser Technology, Sacramento, $\mathrm{CA}$ ) and a $532 \mathrm{~nm}$ diode-pumped solid-state laser (Cobolt Samba $100 \mathrm{~mW}$, Cobolt $\mathrm{AB}$, Solna, Sweden). The microscope was equipped with a Lumen 200 metal arc lamp (Prior Scientific Instruments, Jena, Germany) to provide fluorescence excitation in epi-illumination. Excitation and detection of fluorescence was achieved using a $\times 63$, NA1.46 alpha-Plan-Apochromat oil immersion objective from Zeiss. Fluorescence filters: Unless otherwise mentioned we used the following filter sets from Semrock (Lake Forest, IL): 1) for CC1 $\triangle \mathrm{C} 223$ proteins, BL HC 482/18, BL HC R488, BL HC 520/35 and 2) for rhodamine-labeled MTs, BL HC 520/35, zt 532 RDC from Chroma (Bellows Falls, VT), HC 585/40. Image acquisition: for capturing fluorescence, we used an electron-multiplied charge-coupled device camera (iXon DV 897E, Andor, Belfast, Northern Ireland). The CC1 $\Delta$ C223 proteins were imaged using a continuous recording mode (streaming; duration $50 \mathrm{~s}$ at 10 frames per s) of the MetaMorph imaging software (Molecular Devices, Sunnyvale, CA).

The recorded movies of the in vitro assays were analysed using the open-source softwares Fiji ${ }^{52-54}$ and FIESTA ${ }^{56}$. Movies were background subtracted and frameregistered using standard plugins of Fiji. The intensity of microtubules and CF488A-labeled CC1 $\triangle \mathrm{C} 223$ proteins were measured in average projections of over 500 frames (=50 s) using 10-pixel-wide cross-sects through the microtubule and $\mathrm{CC} 1 \Delta \mathrm{C} 223$ tracks, respectively. The microtubule numbers in the bundles were counted by starting out measuring the intensity of clearly visible single microtubules. Next we measured the intensity of regions where two single microtubules merged into a defined doublet. Occasionally, we found regions where doublets were joined by another single microtubule. At best, we could differentiate up to five microtubules within one bundle. We then compared the intensity of the different microtubule bundles to the intensity of the CC1 $\Delta \mathrm{C} 223$ proteins accumulated at those regions. The lifetime of $\mathrm{CC} 1 \Delta \mathrm{C} 223$ proteins on the microtubules was measured by hand using the kymograph tool of FIESTA. Lifetime was measured from the first appearance of a $\mathrm{CC} 1 \Delta \mathrm{C} 223$ foci until its disappearance. The mean square displacement (MSD) of the CC1 $\triangle \mathrm{C} 223$ proteins was measured by using FIESTA to analyze the diffusion of mobile foci on MTs. After tracking their positions and manually curating the tracks, we calculated the MSD using the corresponding FIESTA plugin.

Microtubule assembly for NMR. Porcine brain tubulin was purified as described in ref. ${ }^{57}$. Tubulin was polymerized in microtubule assembly buffer with $100 \mathrm{mM}$ Na-Pipes, pH 6.9, 1 mM EGTA, $1 \mathrm{mM} \mathrm{MgSO}$, $1 \mathrm{mM}$ GTP and $1 \mathrm{mM}$ DTT. The concentration of tubulin ranged from 10 to $40 \mu \mathrm{M}$ and taxol was added in equimolar concentration. The sample was incubated at $37^{\circ} \mathrm{C}$ for $45 \mathrm{~min}$ and fractionated by ultracentrifugation at $100,000 \times g$ for $1 \mathrm{~h}$. For NMR experiments the pellet was resuspended in a 1:1 mixture of the microtubules assembly buffer and $50 \mathrm{mM}$ Tris- $\mathrm{HCl}$ (pH 7.4), $200 \mathrm{mM} \mathrm{NaCl}$. Electron microscopy showed that the microtubules remained stable during the course of the experiments.

NMR spectroscopy and data analysis. All experiments were performed at $20^{\circ} \mathrm{C}$ at 600 and $750 \mathrm{MHz}$ Bruker Avance spectrometers (Bruker, Karlsruhe, Germany) equipped with cryogenically cooled triple resonance probe heads on samples containing $10 \% \mathrm{D}_{2} \mathrm{O}$ in the above mentioned buffer ratio. The raw NMR data were collected and processed using the TopSpin software (Bruker, Karlsruhe, Germany). Free ${ }^{15} \mathrm{~N},{ }^{13} \mathrm{C}$-labeled $\mathrm{CC} 1 \triangle \mathrm{C} 223$ was assigned using three-dimensional HNCACB, $\mathrm{HN}(\mathrm{CO}) \mathrm{CACB}$ and four-dimensional HNCOCA and HNCACO experiments. The two 3D experiments were acquired each with $512 \times 44 \times 64$ complex data points in the direct $F_{3}\left({ }^{1} \mathrm{H}\right)$ and the two indirect $F_{2}\left({ }^{15} \mathrm{~N}\right), F_{1}\left({ }^{13} \mathrm{C}\right)$ dimensions resulting in $51 \mathrm{~ms}, 22 \mathrm{~ms}$ and $6.4 \mathrm{~ms}$ of acquisition time, respectively. The $4 \mathrm{D}$ data were acquired using non-uniform-sampling with $22 \%$ sparse sampling and reconstructed using the MDD routine implemented in the Bruker TopSpin processing software. All spectra were recorded as BEST-type experiments on a sample with a $250 \mu \mathrm{M}$ concentration ${ }^{58,59}$. Intensity ratios were calculated based on BEST-type HNCA spectra recorded on $150 \mu \mathrm{M}$ uniformly ${ }^{15} \mathrm{~N}-{ }^{13} \mathrm{C}$-labeled samples of $\mathrm{CC} 1 \Delta \mathrm{C} 223$ and CC1 $\triangle \mathrm{C} 223 \mathrm{YYAA}$ alone and in the presence of $100 \mu \mathrm{M}$ microtubules. Each experiment was acquired with 16 scans and $512 \times 36 \times 44$ complex data points, corresponding to an acquisition time of $51 \mathrm{~ms}$ in $F_{3}\left({ }^{1} \mathrm{H}\right), 22 \mathrm{~ms}$ in $F_{2}$ $\left({ }^{15} \mathrm{~N}\right)$ and $11 \mathrm{~ms}$ in $F_{1}\left({ }^{13} \mathrm{C}\right)$, respectively. The total measurement time of each experiment was $20 \mathrm{~h}$. The chemical shift analysis for the detection of structure propensity utilized the random-coil chemical shift library ncIDP ${ }^{28}$. The chemical shifts were automatically referenced using the method described by Marsh et al. ${ }^{60}$

The ${ }^{15} \mathrm{~N}-R_{2},{ }^{15} \mathrm{~N}-R_{1}$ and CPMG relaxation dispersion measurements were carried out using a ${ }^{1} \mathrm{H}-{ }^{15} \mathrm{~N}$ HSQC-based experiment which was recorded as a pseudo 3D with single-FID interleaving and Waltz- $16{ }^{15} \mathrm{~N}$-decoupling during acquisition periods. Each $2 \mathrm{D}$ plane was comprising $512 \times 128$ complex data points in the ${ }^{1} \mathrm{H}$ (direct, $F_{2}$ ) and ${ }^{15} \mathrm{~N}$ (indirect, $F_{1}$ ), corresponding to $51 \mathrm{~ms}$ and $55 \mathrm{~ms}$ of acquisition time, respectively. For the ${ }^{15} \mathrm{~N}-R_{2}$ experiment, a relaxationcompensated Carr-Purcell-Meiboom-Gill (CPMG) scheme at an effective CPMG field of $550 \mathrm{~Hz}$ was applied and relaxation delays were set to $16,32,48,80,112$, 144, $200 \mathrm{~ms}$ with 16, 80 and $144 \mathrm{~ms}$ recorded twice within one experiment. In the ${ }^{15} \mathrm{~N}-R_{1}$ experiments the relaxation delays were measured with $80(2 \times), 240,400$ $(2 \times), 640,880(2 \times), 1280$ and $1600 \mathrm{~ms}$ as set delays.

CPMG relaxation dispersion experiments were measured at CPMG fields, $v_{\mathrm{CP}}$, of $80,160,240,320,400(2 \times), 640,800,1000 \mathrm{~Hz}$, with $v_{\mathrm{CP}}=1 /\left(2 \tau_{\mathrm{CP}}\right)$ and $\tau_{\mathrm{CP}}$ is the time between $180^{\circ}{ }^{15} \mathrm{~N}$-pulses, which were applied for a constant transverse relaxation time of $100 \mathrm{~ms}$ for each CPMG field.

${ }^{15} \mathrm{~N}-R_{2}$ and ${ }^{15} \mathrm{~N}-R_{1}$ experiments were acquired with 16 scans and relaxation dispersion experiments with 64 scans. All experiments employed an interscan delay of $1.3 \mathrm{~s}$ resulting in a total measurement time of $17.5 \mathrm{~h}$ for the ${ }^{15} \mathrm{~N}-R_{2}, 23.5 \mathrm{~h}$ for the ${ }^{15} \mathrm{~N}-R_{1}$ experiment and $26 \mathrm{~h}$ for the relaxation dispersion data. To gain ${ }^{15} \mathrm{~N}-R_{2}$ and ${ }^{15} \mathrm{~N}-R_{1}$ values, the cross-peaks in the $2 \mathrm{D}$ spectra were picked manually and fitted to an exponential function with the software CCPN Analysis. For each fit the error (standard deviation) was estimated using the "covariance" error method. ${ }^{15} \mathrm{~N}-R_{2, \text { eff }}$ values were determined as described in ref. ${ }^{61} .{ }^{1} \mathrm{H}-{ }^{15} \mathrm{~N}$ NOE values were determined by analysing the ratios of peak intensities in paired NMR spectra with and without $3 \mathrm{~s}$ of proton saturation in 64 scans.

All relaxation experiments were recorded on $100 \mu \mathrm{M}$ uniformly ${ }^{15} \mathrm{~N}$-labeled $\mathrm{CC} 1 \Delta \mathrm{C} 223$ before and after adding $25 \mu \mathrm{M}$ of microtubules. All data were apodized with $90^{\circ}$-shifted sine function and zero-filled to yield appropriate data matrices.

Saturation-transfer difference NMR spectra were recorded using a series of equally spaced $20 \mathrm{~ms}$ Gaussian-shaped pulses for a total saturation time of $2 \mathrm{~s}$ and an interscan delay of $5 \mathrm{~s}$. On- and off-resonance frequencies were set to $-0.5 \mathrm{ppm}$ and $60 \mathrm{ppm}$, respectively. The measurements were performed on samples containing $1 \mathrm{mM}$ CC1-peptide and $25 \mu \mathrm{M}$ microtubules in the above mentioned buffer ratio. The $2 \mathrm{D}^{1} \mathrm{H}-1{ }^{13} \mathrm{C}$ HMQC were recorded on the sample with $1024 \times 128$ complex data points, corresponding to an acquisition time of $69 \mathrm{~ms}$ in the ${ }^{1} \mathrm{H}$ (direct, $F_{2}$ ) and $14 \mathrm{~ms}$ in the ${ }^{13} \mathrm{C}$ (indirect, $F_{1}$ ) dimension. Applying an interscan delay of $1.3 \mathrm{~s}$ and 256 scans, the experiment's duration was $25 \mathrm{~h}$.

Sequence conservation. Tau and CC1 evolutionary sequence conservation was calculated by CONSURF on approximately 300 closest homologous sequences identified by BLAST for each protein ${ }^{62,63}$.

Analytical ultracentrifugation. Sedimentation velocity (SV) experiments were performed using a Beckman Optima XL-I analytical ultracentrifuge. Two-channe centerpieces were loaded with $400 \mu \mathrm{l}$ samples of CC1 $1 \Delta \mathrm{C} 223$ in dialysis buffer at concentrations ranging from 15 to $60 \mu \mathrm{M}$. SV runs were carried out overnight at $35,000 \mathrm{rpm}$, at $20^{\circ} \mathrm{C}$. Absorbance scans at $280 \mathrm{~nm}$ were collected every $5 \mathrm{~min}$. Sedimentation coefficient distributions $c(\mathrm{~s})$ were determined using the program Sedfit ${ }^{64}$. The partial-specific volume of CC1 $1 \Delta$ C 223 was predicted as $0.709 \mathrm{ml} / \mathrm{g}$ based on its amino acid sequence using Sednterp ${ }^{65}$. Figures were created with GUSSI (available at http://biophysics.swmed.edu/MBR/software.html).

Circular dichroism spectroscopy. $6 x$ His-CC1 $\Delta \mathrm{C} 223$ was dialyzed against pure water overnight at $4^{\circ} \mathrm{C}$. The sample was spun down at $20,000 \times g$ for $10 \mathrm{~min}$, the supernatant consisting of soluble protein was diluted to $0.1 \mathrm{mg} / \mathrm{ml}$ and transferred into a $0.1 \mathrm{~mm}$ path length cuvette. The background was recorded with pure water Circular dichroism (CD) spectra were recorded at room temperature (approx. $22^{\circ} \mathrm{C}$ ) on a Jasco-715 spectropolarimeter (Jasco Analytical Instruments, USA) which was constantly purged with $\mathrm{N}_{2}$. A total of 4 spectra were accumulated for each measurement with a response time of $4 \mathrm{~s}, 1 \mathrm{~nm}$ data pitch and a $1 \mathrm{~nm}$ bandwidth from 260 to $186 \mathrm{~nm}$. The mean residue weight (mean residue ellipticity) was calculated using the following equation:

$\theta \mathrm{MRW}=(\theta(\lambda) \times 0.1) /(n \times c \times d) ; \theta(\lambda)=$ recorded spectra in millidegrees, $n=$ number of amino acid residues, $c=$ sample concentration in $\mathrm{mol} / \mathrm{l}$, and $d=$ path length of the cuvette in $\mathrm{cm}$.

Microtubule affinity assay. Microtubule spin down assays were performed as described in detail before ${ }^{66}$. Briefly, a constant amount of polymerized tubulin (i.e. microtubules) was incubated with increasing concentrations of either 6xHis$\mathrm{CC} 1 \Delta \mathrm{C} 223$ or $6 \mathrm{xHis}-\mathrm{CC} 1 \Delta \mathrm{C} 223 \mathrm{YYAA}$ ranging from 0 to $30 \mu \mathrm{M}$. The samples were incubated for $30 \mathrm{~min}$ at RT and subsequently spun at $30,000 \times g$ for $30 \mathrm{~min}$ at RT to pellet microtubules and bound proteins. Supernatant and pellet fractions were subjugated to SDS-PAGE and protein levels in both supernatant and pellet 
fractions were analyzed using the Gel-function of Fiji. Final dissociation constant $\left(K_{\mathrm{D}}\right)$ was estimated by fitting a saturation binding curve onto the data points with GraphPad Prism v8.0 (GraphPad software, Inc., USA).

Cell wall analysis. To quantify the cellulose content under salt stress, wild-type and mutant seedlings were grown on control plates (MS media) for 2 days and then transferred to plates containing $150 \mathrm{mM} \mathrm{NaCl}$. After 5 more days of growth, the seed coats were removed and crystalline cellulose was quantified as before ${ }^{67}$.

Live cell-imaging and data processing. XFP-tagged proteins were imaged with a CSU-W1 Yokogawa spinning disc head fitted to a Nikon Eclipse Ti-E inverted microscope with a CFI PlanApo $\times 100$ N.A. 1.40 oil immersion objective, an EMCCD ImageEM 1K (C9100-14) (Hamamatsu Photonics, Japan), and a $\times 1.2$ lens between the spinning disc and camera. GFP was imaged using a $488 \mathrm{~nm}$ solid-state diode laser and a 525/50 nm emission filter, RFP was detected with a $561 \mathrm{~nm}$ solidstate diode laser and a 609/54 nm emission filter. Time lapse images were processed and analyzed with Fiji. Drifts were corrected by using the plugin StackReg or MultiStackReg in cases where two channels were imaged ${ }^{68}$. When the drift of samples could not be corrected in this way, they were excluded from the analysis. Backgrounds were subtracted by the "Subtract Background" tool (rolling ball radius, 30-50 pixels). To quantify CC velocities three frames were averaged by "WalkingAverage" and kymograph analysis was performed with the kymograph tool of FIESTA. Co-localization analysis was performed using the JACoP plugin ${ }^{69}$ of Fiji. For the dual-labeled lines GFP-CC1/GFP-CC1YYAA and tdTomato-CesA6 the van Steensel's cross-correlation function (CCF) was determined by shifting one channel in $x$-direction pixel per pixel relative to the corresponding channel and calculating the Pearson coefficient ${ }^{70}$. Correlation maxima at shift $=0$ pixels indicates co-localization of both channels for most fluorescent foci.

Microtubule quantification and particle detection. Microtubule and particle density at the plasma membrane of cells were determined as described before ${ }^{5}$. Briefly, cortical microtubules were quantified using a Matlab (The MathWorks, Natick, USA) based program, which applied a Sobel edge-detection algorithm at various detection thresholds to raw microscopy images. Detection thresholds were determined manually by choosing a threshold that chose most microtubules and least noise pixels. The cell area was subsequently determined by applying expansion and closing steps to the detected edge-pixels and led to enclosed microtubule regions. Microtubule coverage was then calculated by dividing the microtubule area by the cell area. By using a self-written Fiji macro, particle density at the plasma membrane was determined. The cell area was detected by convoluting a wide Gaussian kernel $($ sigma $=1.33$ mum $)$ into each raw image and applying an automated threshold. Particles were subsequently detected by generating a Laplacian image with FeatureJ (Erik Meijering, Biomedical Imaging Group, EPFL Lausanne) from smoothed images (Gaussian kernel with sigma $=0.2 \mu \mathrm{m}$ ). Peaks were detected using the Find Maxima function with a noise tolerance of 800. Analogously, Golgi were detected (Gaussian kernel with sigma $=0.8 \mu \mathrm{m}$; noise tolerance of 120). The number of Golgi was subtracted from the number of total particles. Density was calculated by dividing the resulting particle count by the cell area.

Quantification of microtubule bundling and dynamics. Image analysis was done using Fiji. Cell boundaries were detected by convoluting a wide Gaussian kernel $($ sigma $=10 \mu \mathrm{m})$ into each image and thresholding using the Otsu algorithm ${ }^{71}$. All further operations were conducted within these cell boundaries. To detect microtubules and skeletonize the raw images, a Laplacian image was generated using FeatureJ and smoothing of 1.5 (Erik Meijering, Biomedical Imaging Group, EPFL Lausanne). A user defined threshold was then applied for each individual image that covered all microtubules in the image independently of the background. The "Despeckle Filter" of Fiji was then applied. Microtubules were then detected using the "Analyze Particles" function of Fiji with a size from 20 to infinity pixels and the outside of these was cleared. The skeletonized microtubule image was then analyzed using Diameter ${ }^{72}$ with standard settings. The calculated "Super Pixel" were taken as a measure for mean fiber diameter and therefore bundling of fibers.

Microtubule dynamics were measured as described in detail before ${ }^{5}$. Briefly, time phased image subtraction with a time shift of one frame was applied to identify shrinking and growing microtubule ends. The velocities of these growing and shrinking microtubule ends were finally analyzed with the kymograph evaluation tool of FIESTA.

Statistical analysis and experimental design. For statistical analyses, Welch's unpaired $t$-test or two-way ANOVA were performed using GraphPad Prism 8. A $p$ value of $<0.05$ was considered as statistically significant. Each statistical method used to calculate $p$-values is defined in the corresponding figure legends. Data analysis (especially for images) was either done automatically, so independently from the investigator, or file names were removed before the analysis. For the measurement of plant size, investigators were not blinded. In this case, data were always collected according to the genotype of plants. Sample size was determined for each experiment based on similar data reported in scientific literature.
Reporting summary. Further information on experimental design is available in the Nature Research Reporting Summary linked to this article.

\section{Data availability}

All cross-linking mass spectrometry data are available at PRIDE with the identifier PXD009260. The NMR chemical shift data are deposited in the BMRB database with accession number 27660. Data underlying Fig. 1a, f-h, Fig. 2b, e, 3b-d, Fig. 4c-f, Fig. 5a c, e-h, Fig. S1a, Fig. S3b, c, e, f, Fig. S4a-g, Fig. 5a-e, g, Fig. S6i-j, Fig. S7d-e, g-h are provided as a Source Data file. Any other data are available from the corresponding authors upon request.

Received: 25 September 2018 Accepted: 25 January 2019 Published online: 20 February 2019

\section{References}

1. Roostalu, J. \& Surrey, T. Microtubule nucleation: beyond the template. Nat. Rev. Mol. Cell Biol. 18, 702-710 (2017).

2. Mach, J. Plant cortical microtubule arrays: recruitment mechanisms in common with centrosomes. Plant Cell 24, 2 (2012).

3. Paredez, A. R., Somerville, C. R. \& Ehrhardt, D. W. Visualization of cellulose synthase demonstrates functional association with microtubules. Science 312, $1491-1495$ (2006).

4. McFarlane, H. E., Döring, A. \& Persson, S. The cell biology of cellulose synthesis. Annu. Rev. Plant. Biol. 65, 69-94 (2014).

5. Endler, A. et al. A mechanism for sustained cellulose synthesis during salt stress. Cell 162, 1353-1364 (2015).

6. Ballatore, C., Lee, V. M.-Y. \& Trojanowski, J. Q. Tau-mediated neurodegeneration in Alzheimer's disease and related disorders. Nat. Rev. Neurosci. 8, 663-672 (2007)

7. Arendt, T., Stieler, J. T. \& Holzer, M. Tau and tauopathies. Brain Res. Bull. 126, 238-292 (2016).

8. Kellogg, E. H. et al. Near-atomic model of microtubule-tau interactions. Science 360, 1242-1246 (2018).

9. Drechsel, D. N., Hyman, A. A., Cobb, M. H. \& Kirschner, M. W. Modulation of the dynamic instability of tubulin assembly by the microtubule-associated protein tau. Mol. Biol. Cell 3, 1141-1154 (1992).

10. Hinrichs, M. H. et al. Tau protein diffuses along the microtubule lattice. J. Biol. Chem. 287, 38559-38568 (2012).

11. Scott, C. W., Klika, A. B., Lo, M. M. S., Norris, T. E. \& Caputo, C. B. Tau protein induces bundling of microtubules in vitro: comparison of different tau isoforms and a tau protein fragment. J. Neurosci. Res. 33, 19-29 (1992).

12. Drubin, D. G. \& Kirschner, M. W. Tau protein function in living cells. J. Cell Biol. 103, 2739-2746 (1986)

13. Trojanowski, J. Q., Schuck, T., Schmidt, M. L. \& Lee, V. M. Distribution of tau proteins in the normal human central and peripheral nervous system. J. Histochem. Cytochem. 37, 209-215 (1989).

14. Mucke, L. Neuroscience: Alzheimer's disease. Nature 461, 895-897 (2009).

15. Gardiner, J., Overall, R. \& Marc, J. Distant plant homologues: don't throw out the baby. Trends Plant. Sci. 17, 126-128 (2012)

16. Gardiner, J. The evolution and diversification of plant microtubule-associated proteins. Plant J. 75, 219-229 (2013).

17. Rappsilber, J. The beginning of a beautiful friendship: cross-linking/mass spectrometry and modelling of proteins and multi-protein complexes. $J$. Struct. Biol. 173, 530-540 (2011).

18. Götze, M. et al. StavroX-A software for analyzing crosslinked products in protein interaction studies. J. Am. Soc. Mass Spectrom. 23, 76-87 (2012).

19. Yang, B. et al. Identification of cross-linked peptides from complex samples. Nat. Methods 9, 904-906 (2012).

20. Lima, D. B. et al. SIM-XL: a powerful and user-friendly tool for peptide crosslinking analysis. J. Proteom. 129, 51-55 (2015).

21. Park, C. Y., Klammer, A. A., Käll, L., MacCoss, M. J. \& Noble, W. S. Rapid and accurate peptide identification from tandem mass spectra. J. Proteome Res. 7 , 3022-3027 (2008)

22. Kadavath, $\mathrm{H}$. et al. Tau stabilizes microtubules by binding at the interface between tubulin heterodimers. Proc. Natl Acad. Sci. USA 112, 7501-7506 (2015).

23. Gigant, B. et al. Structural basis for the regulation of tubulin by vinblastine. Nature 435, 519-522 (2005)

24. Ravelli, R. B. G. et al. Insight into tubulin regulation from a complex with colchicine and a stathmin-like domain. Nature 428, 198-202 (2004).

25. Reddy, V., Lymar, E., Hu, M. \& Hainfeld, J. 5 nm Gold-Ni-NTA binds His tags. Microsc. Microanalysis 11, 1118CD (2005). 
26. Gell, C. et al. Microtubule dynamics reconstituted in vitro and imaged by single-molecule fluorescence microscopy. Methods Cell Biol. 95, 221-245 (2010).

27. Tamiola, K. \& Mulder, F. A. A. Using NMR chemical shifts to calculate the propensity for structural order and disorder in proteins. Biochem. Soc. Trans. 40, 1014-1020 (2012).

28. Tamiola, K., Acar, B. \& Mulder, F. A. A. Sequence-specific random coil chemical shifts of intrinsically disordered proteins. J. Am. Chem. Soc. 132, 18000-18003 (2010)

29. Mukrasch, M. D. et al. Structural polymorphism of 441-residue tau at single residue resolution. PLoS Biol. 7, e34 (2009)

30. Sampathkumar, A. et al. Patterning and lifetime of plasma membranelocalized cellulose synthase is dependent on actin organization in Arabidopsis interphase cells. Plant Physiol. 162, 675-688 (2013).

31. Gutierrez, R., Lindeboom, J. J., Paredez, A. R., Emons, A. M. C. \& Ehrhardt, D. W. Arabidopsis cortical microtubules position cellulose synthase delivery to the plasma membrane and interact with cellulose synthase trafficking compartments. Nat. Cell Biol. 11, 797-806 (2009).

32. Cramer, G. R., Urano, K., Delrot, S., Pezzotti, M. \& Shinozaki, K. Effects of abiotic stress on plants: a systems biology perspective. BMC Plant Biol. 11, 163 (2011).

33. Shrivastava, P. \& Kumar, R. Soil salinity: a serious environmental issue and plant growth promoting bacteria as one of the tools for its alleviation. Saudi J. Biol. Sci. 22, 123-131 (2015).

34. Munns, R. \& Tester, M. Mechanisms of salinity tolerance. Annu. Rev. Plant. Biol. 59, 651-681 (2008).

35. Fauquant, C. et al. Systematic identification of tubulin-interacting fragments of the microtubule-associated protein Tau leads to a highly efficient promoter of microtubule assembly. J. Biol. Chem. 286, 33358-33368 (2011).

36. Gigant, B. et al. Mechanism of Tau-promoted microtubule assembly as probed by NMR spectroscopy. J. Am. Chem. Soc. 136, 12615-12623 (2014).

37. Prezel, E. et al. Tau can switch microtubule network organizations: from random networks to dynamic and stable bundles. Mol. Biol. Cell 29, 154-165 (2018).

38. Qiang, L. et al. Tau does not stabilize axonal microtubules but rather enables them to have long labile domains. Curr. Biol. 28, 2181-2189.e4 (2018).

39. Lopes, S. et al. Tau protein is essential for stress-induced brain pathology. Proc. Natl Acad. Sci. USA 113, E3755-E3763 (2016).

40. Ibáñez-Salazar, A. et al. Oxidative stress modifies the levels and phosphorylation state of Tau protein in human fibroblasts. Front. Neurosci. 11, 495 (2017)

41. Chen, J., Kanai, Y., Cowan, N. J. \& Hirokawa, N. Projection domains of MAP2 and tau determine spacings between microtubules in dendrites and axons. Nature 360, 674-677 (1992).

42. Sampathkumar, A. et al. Live cell imaging reveals structural associations between the actin and microtubule cytoskeleton in Arabidopsis. Plant Cell 23, 2302-2313 (2011).

43. Gibson, D. G. et al. Enzymatic assembly of DNA molecules up to several hundred kilobases. Nat. Methods 6, 343-345 (2009).

44. Grefen, C. et al. A ubiquitin-10 promoter-based vector set for fluorescent protein tagging facilitates temporal stability and native protein distribution in transient and stable expression studies. Plant J. 64, 355-365 (2010).

45. Gasteiger, E. et al. Protein identification and analysis Tools on the ExPASy Server. in The Proteomics Protocols Handbook (ed. Walker, J. M.) 571-607 (Humana Press Inc., New Jersey, USA, 2005)

46. Medzihradszky, K. F. In-solution digestion of proteins for mass spectrometry. Methods Enzymol. 405, 50-65 (2006).

47. Laemmli, U. K. Denaturing (SDS) discontinuous gel electrophoresis. Nature 277, 680-685 (1970).

48. Shevchenko, A., Tomas, H., Havlis, J., Olsen, J. V. \& Mann, M. In-gel digestion for mass spectrometric characterization of proteins and proteomes. Nat. Protoc. 1, 2856-2860 (2006).

49. Holman, J. D., Tabb, D. L. \& Mallick, P. Employing ProteoWizard to convert raw mass spectrometry data. Curr. Protoc. Bioinforma. 46, 13.24.1-9 (2014).

50. Strohalm, M., Hassman, M., Kosata, B. \& Kodícek, M. mMass data miner: an open source alternative for mass spectrometric data analysis. Rapid Commun. Mass Spectrom. 22, 905-908 (2008).

51. Vizcaíno, J. A. et al. 2016 update of the PRIDE database and its related tools. Nucleic Acids Res. 44, 11033 (2016).

52. Schindelin, J. et al. Fiji: an open-source platform for biological-image analysis. Nat. Methods 9, 676-682 (2012).

53. Rueden, C. T. et al. ImageJ2: ImageJ for the next generation of scientific image data. BMC Bioinform. 18, 529 (2017).

54. Schneider, C. A., Rasband, W. S. \& Eliceiri, K. W. NIH Image to ImageJ: 25 years of image analysis. Nat. Methods 9, 671-675 (2012).

55. Nitzsche, B. et al. Studying kinesin motors by optical 3D-nanometry in gliding motility assays. Methods Cell Biol. 95, 247-271 (2010).
56. Ruhnow, F., Zwicker, D. \& Diez, S. Tracking single particles and elongated filaments with nanometer precision. Biophys. J. 100, 2820-2828 (2011).

57. Castoldi, M. \& Popov, A. V. Purification of brain tubulin through two cycles of polymerization-depolymerization in a high-molarity buffer. Protein Expr. Purif. 32, 83-88 (2003)

58. Schanda, P., Kupce, E. \& Brutscher, B. SOFAST-HMQC experiments for recording two-dimensional heteronuclear correlation spectra of proteins within a few seconds. J. Biomol. NMR 33, 199-211 (2005)

59. Schanda, P., Van Melckebeke, H. \& Brutscher, B. Speeding up threedimensional protein NMR experiments to a few minutes. J. Am. Chem. Soc 128, 9042-9043 (2006).

60. Marsh, J. A., Singh, V. K., Jia, Z. \& Forman-Kay, J. D. Sensitivity of secondary structure propensities to sequence differences between alpha- and gammasynuclein: implications for fibrillation. Protein Sci. 15, 2795-2804 (2006).

61. Neudecker, P., Lundström, P. \& Kay, L. E. Relaxation dispersion NMR spectroscopy as a tool for detailed studies of protein folding. Biophys. J. 96, 2045-2054 (2009)

62. Berezin, C. et al. ConSeq: the identification of functionally and structurally important residues in protein sequences. Bioinformatics 20, 1322-1324 (2004).

63. Altschul, S. F., Gish, W., Miller, W., Myers, E. W. \& Lipman, D. J. Basic local alignment search tool. J. Mol. Biol. 215, 403-410 (1990).

64. Schuck, P. Size-distribution analysis of macromolecules by sedimentation velocity ultracentrifugation and lamm equation modeling. Biophys. J. 78, 1606-1619 (2000)

65. Hayes, D., Laue, T. \& Philo, J. Program Sednterp: sedimentation interpretation program. (Alliance Protein Laboratories, Thousand Oaks, CA, 1995).

66. Kesten, C., Schneider, R. \& Persson, S. In vitro microtubule binding assay and dissociation constant estimation. Bio-Protoc. 6, e1759 (2016).

67. Sánchez-Rodríguez, C. et al. CHITINASE-LIKE1/POM-POM1 and Its Homolog CTL2 are glucan-interacting proteins important for cellulose biosynthesis in Arabidopsis. Plant Cell Online 24, 589-607 (2012).

68. Thevenaz, P., Ruttimann, U. E. \& Unser, M. A pyramid approach to subpixe registration based on intensity. IEEE Trans. Image Process. 7, 27-41 (1998).

69. Bolte, S. \& Cordelières, F. P. A guided tour into subcellular colocalization analysis in light microscopy. J. Microsc. 224, 213-232 (2006).

70. van Steensel, B. et al. Partial colocalization of glucocorticoid and mineralocorticoid receptors in discrete compartments in nuclei of rat hippocampus neurons. J. Cell Sci. 109(Pt 4), 787-792 (1996).

71. Otsu, N. A threshold selection method from gray-level histograms. IEEE Trans. Syst. Man Cybern. 9, 62-66 (1979).

72. Hotaling, N. A., Bharti, K., Kriel, H. \& Simon, C. G. Jr. DiameterJ: a validated open source nanofiber diameter measurement tool. Biomaterials 61, 327-338 (2015).

73. Zhang, X. et al. Heat-shock response transcriptional program enables highyield and high-quality recombinant protein production in Escherichia coli. ACS Chem. Biol. 9, 1945-1949 (2014).

\section{Acknowledgements}

Live cell imaging was performed with equipment maintained by the Center for Microscopy and Image Analysis (University of Zurich) and Scientific Center for Optical and Electron Microscopy (ScopeM, ETH Zurich). We thank Martina Leidert and Natalja Erdmann for help with protein expression and purification and Ines Kretschmar for synthesizing the peptides. We thank Dmytro Puchkov for performing the MT quality control by EM and Tim Scholz (Hannover Medical School) for assistance with the microtubule purification protocol. We also thank the Diez group, especially Felix Ruhnow, (B CUBE Center for Molecular Bioengineering, Dresden) for assistance with microtubule imaging and in vitro assays. The helper plasmid pBAD- $\sigma 32$ (I54N) was a gift from Jeffery Kelly ${ }^{73}$ (Addgene plasmid \# 59982), pETM11 was kindly supplied by EMBL Protein Production facility (Heidelberg Germany). We thank the Biological Optica Microscopy Platform, the Melbourne Advanced Microscopy Facility, and the Mass Spectrometry and Proteomics Facility (School of Biosciences and Bio21) at the University of Melbourne. S.P. was supported by an ARC Discovery grant (DP190101941), a Hermon-Slade Grant (Persson HSF 15/4) and a Future Fellowship grant (FT160100218). J.L.H. was supported by an ARC Future Fellowship (FT130101165). H.E.M. was supported by an ARC DECRA (DE170100054). C.S.R. and C.K. were supported by ETHZ and a SNF grant (2-77212-15). R.S. received Computational Biology Research Initiative and Early Career Research Grants from the University of Melbourne. C.K. was supported by a Peter und Traudl Engelhorn-Stiftung fellowship.

\section{Author contributions}

C.K., A.W., R.S., H.E.M., A.D., B.J.v.R., E.R.L., J.H., C.S.R., H.O. and S.P. designed the research. C.K., A.W., R.S., H.E.M., A.D., M.L., G.A.K., N.C., P.S., F.S. and K.F. performed the research. C.K., A.W., R.S., H.E.M., W.G.S., J.H. and S.P. analyzed data. C.K., A.W., C. S.R., H.O. and S.P. wrote the article. C.K. and A.W. share equal first authorship. 


\section{Additional information}

Supplementary Information accompanies this paper at https://doi.org/10.1038/s41467019-08780-3.

Competing interests: The authors declare no competing interests.

Reprints and permission information is available online at http://npg.nature.com/ reprintsandpermissions/

Journal peer review information: Nature Communications thanks the anonymous reviewers for their contribution to the peer review of this work. Peer reviewer reports are available.

Publisher's note: Springer Nature remains neutral with regard to jurisdictional claims in published maps and institutional affiliations. (c) (i) Open Access This article is licensed under a Creative Commons Attribution 4.0 International License, which permits use, sharing, adaptation, distribution and reproduction in any medium or format, as long as you give appropriate credit to the original author(s) and the source, provide a link to the Creative Commons license, and indicate if changes were made. The images or other third party material in this article are included in the article's Creative Commons license, unless indicated otherwise in a credit line to the material. If material is not included in the article's Creative Commons license and your intended use is not permitted by statutory regulation or exceeds the permitted use, you will need to obtain permission directly from the copyright holder. To view a copy of this license, visit http://creativecommons.org/ licenses/by/4.0/.

Crown 2019 